\title{
ENFOQUES NORMATIVOS SOBRE LAS PRÁCTICAS DESLEALES EN LA CADENA AGROALIMENTARIA. ATENCIÓN A LAS EMPRESAS DE ECONOMÍA SOCIAL Prácticas desleales y empresas de economía social
}

\author{
Trinidad Vázquez Ruano \\ Catedrática (acreditada) de Derecho mercantil \\ Universidad de Jaén
}

ORCID: 0000-0001-9324-890X

\section{RESUMEN}

En el mercado de productos agroalimentarios es necesario identificar los presupuestos normativos que ofrecen un nivel adecuado de competencia en beneficio de su correcto funcionamiento y de la protección de los que participan en dicho mercado. Esto es, los operadores que intervienen en la figurada cadena que une "el campo con la mesa", con especial atención a las empresas de economía social. La Comisión Europea se ha preocupado del sector vulnerable en la cadena de suministro de alimentos (Directiva (UE) 2019/633, de 17 de abril). Nuestro legislador ha aprobado el Real Decreto-ley 5/2020 de medidas urgentes en materia de agricultura y alimentación y la Ley 16/2021, de 14 de diciembre, de reforma de la Ley de la Cadena Alimentaria. Sin embargo, y aun cuando se fomenta la innovación en la cadena alimentaria, la transparencia y se incrementa el reparto más justo del valor, la CNMC ha planteado algunas observaciones en negativo al contenido de la reforma.

PALABRAS CLAVE: Cadena agroalimentaria, prácticas comerciales desleales, CNMC, competencia, situaciones de desequilibrio, entidades de economía social.

CLAVES ECONLIT / ECONLIT DESCRIPTORS: A19, D18, K21, L10, M21, P130.

Cómo citar este artículo/How to cite this article: VÁZQUEZ RUANO, T.: "Enfoques normativos sobre las prácticas desleales en la cadena agroalimentaria. Atención a las empresas de economía social. Prácticas desleales y empresas de economía social", CIRIEC-España, Revista Jurídica de Economía Social y Cooperativa, n³ 39, 2021, pp. 199-240.

DOI: 10.7203/CIRIEC-JUR.39.20903 


\section{PROPOSAL TO REGULATE UNFAIR PRACTICES IN THE AGRI-FOOD CHAIN. ATTENTION TO SOCIAL ECONOMY COMPANIES. Unfair practices and social economy companies}

\section{EXPANDED ABSTRACT}

In the agri-food products market, it is necessary to determine the regulatory budgets that provide an adequate level of competition for the benefit of its proper functioning and the protection of those who participate in said market. The subjects that participate in the agri-food market must be understood in a broad sense. In other words, in relation to all the operators involved in the figurative chain that links 'the field with the table', with special attention to social economy companies. Specifically, it is necessary to refer to entrepreneurs, distributors, manufacturers, consumers, farmers and any other subject that participates in the aforementioned market.

One of the main concerns of the European Commission in the agricultural and food sector has been the protection and guarantee of the interests of small and medium-sized food and agricultural companies, producers and farmers. As these are considered the vulnerable sector in the food supply chain both because of their disadvantage in the ability to negotiate with larger operators and because of their position in contractual relationships in the market.

The reflection of this concern was the approval of Directive (EU) 2019/633 of the European Parliament and of the Council of 17 April 2019 on unfair trading practices in business-to-business relationships in the agricultural and food supply chain. This regulatory text was approved by a large majority and its content will be mandatory for EU member countries before November of this year. The European Commission has to evaluate the effectiveness of the provisions of the standard in the internal market and its consequences before the end of 2025.

The unfair actions that try to limit themselves are commercial practices that violate the principles of good faith and fair trade in the agri-food market that are imposed unilaterally by a contractual party (the largest) and without the counterpart having the bargaining power, except for the mere acceptance of the specific contractual content. The specific object of Directive (EU) 2019/633 is expressly specified in the limitation of: commercial practices that grossly deviate from good commercial conduct, that are contrary to good faith and fair dealing and that are unilaterally imposed by one trading partner on another.

The protection provided by this Directive should benefit agricultural producers and natural or legal persons that supply agricultural and food products (including producer organisations), 
and associations of producer organisations. Those producer organisations and associations of producer organisations include cooperatives. Cooperatives being social economy entities.

The reference rule intends to limit unfair commercial practices in the food supply chain, which imply the alteration of equal opportunities for small and medium-sized agricultural and food companies, producers and farmers. Mainly because of the diverse bargaining power of these parties in the contract. This has been stated by the European Commission in the proposals to modernize the Common Agricultural Policy (CAP) 2021-2027. This has been stated by the European Commission in the proposals to modernize the Common Agricultural Policy (CAP) 2021-2027. Specifically, the legislative initiatives on updating the CAP as of 2020, the purpose of which is for the Agrarian Policy to respond to the present and future challenges of this sector, such as: climate change or generational change. That is to say, that it contributes to the European Green Deal (2019), first, objectives on the environment and action for the climate; and, second, equitable treatment and economic stability, preserving the special position of agriculture in European society.

Fair competition in the market requires ensuring competition and guaranteeing the proper exercise of the freedom of business of those who are part of the market. Business freedom is the recognition of free entrepreneurial initiative in the entire economic system and under equal conditions for those who develop it and regardless of the forms of their organization. And it is the public powers that have to protect their exercise and productivity according to the demands of the general economy and market planning. Effective competition will define the market economy and this affects the consumer through the offer of products and / or services and with the determination of their final price.

In addition, free competition in the market requires the guarantee of the interests of the rest of the participants in the economic environment, which includes the behaviors that are carried out in said market for concurrent purposes. A diversity of operators participate in the agricultural and food supply chain: agents of production, transformation, marketing, distribution and retail of these products. Consequently, unfair commercial practices have direct effects on agricultural producers and their organizations (suppliers) and, indirectly, on all primary producers.

Our legislator has approved RD-Law 5/2020, on urgent measures in the field of agriculture and food, and the Law 16/2021 reform of the Food Chain Law. The aim of these new reforms is to promote innovation in the food chain, give transparency to its operation and increase the fairer distribution of value. But, nevertheless, the National Commission of Markets and Competition (CNMC) has made some negative observations to its content. The fundamental aspects that the Competition Commission questions are the following. First, the material and 
territorial scope of the reform, which refers to any commercial operation. The question arises because it is not specified that the commercial performance generates an imbalance between the contracting parties. Second, the regime of unfair commercial practices in the agri-food chain. A minimum transposition is made and the current unfair behavior is maintained and other new practices are incorporated. But not all prohibited behaviors included in the "black practices" and "gray practices" lists are not accepted. Nor does the rule refer to the order of regulatory application on unfair practices in the market (unfair competition rule, trademark regulation, antitrust rule, regulation of retail trade or rule on business secrets). Finally, the Competition Commission studies the sanctioning regime and the infractions. The sanctioning regime is simplified and coordination measures are established for the agri-food sector and other sanctioning authorities. The Commission points out the need to strengthen cooperation between the entities that have sanctioning powers and those that are supervisors. And it is also necessary to specify the compensation system applicable to subjects who do not comply with the rules.

KEYWORDS: Agri-food chain, unfair business practices, National Market and Competition Commission, competition, situations of imbalance, social economy entities. 


\section{SUMARIO $^{1}$}

I. Ideas Preliminares. II. El mercado agroalimentario y las conductas comerciales desleales. Ámbito comunitario. A. Referencias precedentes. B. La regulación de las prácticas comerciales desleales en la cadena de suministro agrícola y alimentario. III. Régimen normativo interno sobre los comportamientos desleales. Especial referencia al sector agroalimentario. A. Indicaciones sobre las previsiones generales que regulan la competencia en el mercado y el sector agroalimentario. B. Especial referencia a la precursora Ley 12/2013 de medidas para mejorar el funcionamiento de la cadena alimentaria. IV. La adecuación de la regulación nacional a las previsiones comunitarias sobre la cadena alimentaria. Intervención de la CNMC al respecto. A. Comentarios previos. B. Orientaciones realizadas por la Comisión de Competencia. C. Repercusiones de la reforma normativa en las entidades de economía social. V. Recopilaciones finales. Bibliografía.

\section{Ideas preliminares}

Los nuevos aspectos objeto de regulación a nivel europeo en lo que concierne a los comportamientos comerciales que se llevan a cabo entre entidades que forman parte de la cadena agroalimentaria se han recogido en la Directiva (UE) 2019/633, de 17 de abril, relativa a las prácticas comerciales desleales en las relaciones entre empresas en la cadena de suministro agrícola y alimentario ${ }^{2}$. Texto normativo aprobado por una amplia mayoría ${ }^{3}$ y cuyo contenido, como queda previsto en su propio tenor, será de obligado cumplimiento para los países miembros de la UE antes del mes de noviembre de este mismo año. Razón por la que la Comisión Europea ha de evaluar la eficacia de sus previsiones en el mercado interior y las consecuencias de las mismas con anterioridad a la finalización del $2025^{4}$.

1. Este trabajo se vincula a las investigaciones realizadas en el marco del Equipo de Investigación de la Universidad de Jaén EI_SEJ2 y del Proyecto de Investigación "Trust and security in the olive market: Un etiquetado orientado al mercado que informe y proteja a los consumidores" del Instituto de Estudios Giennenses de la Diputación Provincial de Jaén (2020), de los cuales soy IP.

2. Directiva (UE) 2019/633, del Parlamento Europeo y del Consejo, de 17 de abril de 2019, relativa a las prácticas comerciales desleales en las relaciones entre empresas en la cadena de suministro agrícola y alimentario (DOUE L111, 25 de abril de 2019).

3. La votación fue la siguiente: 589 votos a favor, 72 en contra y 9 abstenciones.

4. En el mes de noviembre de 2025. 
El mercado de productos agroalimentarios y sus peculiaridades precisan que se atiendan y observen, de manera particular, los presupuestos que proporciona el ordenamiento y que tienen por finalidad ofrecer un nivel adecuado de competencia en beneficio de su correcto funcionamiento y, de modo especial, en lo que hace a la protección y garantía de los que participan en dicho mercado en un sentido amplio 5 . Es decir, en relación con los empresarios, distribuidores, fabricantes, consumidores, agricultores y cualquier otro sujeto que concurra en el mencionado mercado.

Las iniciativas legislativas aplicables al mercado de productos agroalimentarios han estado centradas en la protección de los intereses de los consumidores y, de forma genérica, de los operadores económicos que intervienen en este sector comercial. Sin embargo, en estas previsiones normativas, quedaban fuera de tutela específica las pequeñas y medianas empresas alimentarias y agrícolas y los productores y agricultores de la cadena de suministro de alimentos. En este sentido, la Comisión Europea estimó centrar su atención en la seguridad de los intereses de los referidos sujetos al entender que se trata de un sector no sólo que, en parte, quedaba al margen de aquel ámbito de protección ${ }^{6}$, sino porque ha de considerarse un grupo vulnerable de la cadena de valor. Más aún por la desventaja que presenta respecto a la capacidad de negociar con los operadores de mayor tamaño o en lo que se refiere a su posición en las relaciones contractuales desarrolladas entre ellos en el mercado 7 .

En razón de lo anterior, el texto normativo de referencia en la materia pretende limitar las posibles prácticas comerciales desleales ejercidas en la cadena de suministro alimentario y que suponen la alteración de la igualdad de oportunidades de las pequeñas y medianas empresas agrícolas y alimentarias, de los productores y de los agricultores. Fundamentalmente en base al diverso poder de negociación con el que dichas partes cuentan, tal y como lo ha puesto de manifiesto la Comisión Europea en las

5. Para ampliar esta consideración, puede consultarse nuestro trabajo previo: VÁZQUEZ RUANO, T.: "Cuestiones de Derecho español sobre publicidad y competencia en el sector agroalimentario", Przeglad Prawa Rolnego, no 1(16), 2015, pp. 245-263.

6. Propuesta Unfair trading practices in the food chain, Bruselas, 12 de abril de 2018 (SWD (2018) 92 final. Commission Staff Working Document Impact Assessment Initiative to Improve the Food Supply Chain (unfair trading practices)).

7. Atendiendo al contenido del documento de la Commission Staff Working Document Impact Assessment Initiative to Improve the Food Supply Chain (unfair trading practices) de 2018, las prácticas desleales hacen que las pymes agrícolas y dedicadas al procesado de alimentos pierdan 2.500 y 8.000 millones de euros al ańo aproximadamente (casi un $2 \%$ de su facturación) como consecuencia de las mismas. Pueden consultarse en el espacio electrónico siguiente:

https://eur-lex.europa.eu/legal-content/EN/TXT/PDF/?uri=CELEX:52018SC0092\&from=EN 
propuestas de modernización de la Política Agrícola Común (PAC) 2021-2027². En concreto, las iniciativas legislativas sobre la actualización de la PAC a partir de 2020 presentadas en junio de 2018 y que tienen por objeto que la Política Agraria responda de una mejor forma a los retos presentes y futuros de este sector, como lo son: el cambio climático o el relevo generacional. Es decir, que aporte de modo significativo al Pacto Verde Europeo', de un lado, en cuanto a los objetivos sobre el medio ambiente y la acción por el clima; y, de otro, ofreciendo al sector un trato equitativo y estabilidad económica, conservando el posicionamiento con el que cuenta la agricultura en la sociedad europea.

Las actuaciones desleales que tratan de limitarse, en el ámbito que nos ocupa, van a ser las prácticas comerciales que infringen los principios de buena fe y comercio justo en el mercado agroalimentario en la medida en que son impuestas de manera unilateral por una parte contractual (la de tamaño mayor) y ello implica que la contraparte apenas disponga de margen de negociación, más allá de la mera aceptación del contenido contractual ya determinado. De acuerdo con esta consideración, el objeto específico que singulariza las previsiones de la Directiva (UE) 2019/633 se concreta de modo expreso en la limitación de:

(...) las prácticas comerciales desleales ... en términos de igualdad de oportunidades para las pequeñas y medianas empresas alimentarias y agricolas, los productores y los agricultores, al comprender cuál es un sector vulnerable en la cadena de suministro.

La garantía de la leal competencia en el mercado requiere que ésta se asegure y, al mismo tiempo, se garantice el adecuado ejercicio de la libertad de empresa de los

8. Pueden consultarse en el espacio electrónico siguiente: https://ec.europa.eu/info/food-farming-fisheries/ key-policies/common-agricultural-policy/future-cap_es. Aunque, las negociaciones en curso entre el Parlamento Europeo y el Consejo hacen que la fecha provisional de inicio de la reforma propuesta de la PAC está prevista para el 1 de enero de 2023. Por ello, una vez que se han asignado los fondos de la PAC (2021-2027), se ha aprobado un Reglamento de transición para los años 2021 y 2022 (Reglamento (UE) 2020/2220 del Parlamento Europeo y del Consejo, de 23 de diciembre, por el que se establecen determinadas disposiciones transitorias para la ayuda del Fondo Europeo Agrícola de Desarrollo Rural (Feader) y del Fondo Europeo Agrícola de Garantía (FEAGA) en los ańos 2021 y 2022, y por el que se modifican los Reglamentos (UE) $1305 / 2013$, (UE) 1306/2013 y (UE) 1307/2013 en lo que respecta a sus recursos y a su aplicación en los ańos 2021 y 2022 y el Reglamento (UE) 1308/2013 en lo que respecta a los recursos y la distribución de dicha ayuda en los años 2021 y 2022. DOUE L437, de 28 de diciembre) que va a prorrogar las normas de la PAC vigentes durante el período 2014-2020.

9. Comunicación de la Comisión El Pacto Verde Europeo (COM (2019) 640 final. Bruselas, 11 de diciembre de 2019) en el marco de la Estrategia "De la Granja a la Mesa» y de la Estrategia sobre Biodiversidad. 
que forman parte del mercado y que se vincula a la necesaria unidad económica y a la concepción del mercado único ${ }^{10}$. Libertad de empresa que, como es sabido, se concreta en el reconocimiento de la libre iniciativa empresarial en el conjunto del sistema económico y en igualdad de condiciones para los que la llevan a cabo y con independencia de las formas de su organización. Debiendo ser los poderes públicos los que garanticen y protejan su ejercicio y la defensa de la productividad en relación con las exigencias de la economía general y de la planificación del mercado. De este modo, se trata del reconocimiento de la facultad de acceder a un mercado con libre iniciativa empresarial y que, a su vez, se determinen las condiciones del desarrollo de la actividad comercial, el libre ejercicio sobre la finalidad y objetivos económicos en cada caso y la posibilidad de cesar en la actividad cuando lo estime conveniente el empresario.

La efectiva competencia va a definir la economía de mercado y ello tiene una notable repercusión en el consumidor tanto en lo que concierne a la oferta de productos y/o servicios, como en relación con la determinación del precio final de los mismos. Esta precisión conceptual se vincula a la adecuada protección de los intereses de los que, formando parte del mercado, ostentan la condición de consumidores de productos/bienes o, en su caso, usuarios de los servicios que se ofertan en él ${ }^{11}$.

Asimismo, la libre competencia en el mercado requiere de la garantía de los intereses del resto de participantes en el entorno económico, lo que comprende los comportamientos que se realizan en dicho mercado con fines concurrenciales. $\mathrm{Si}$ bien, en un sentido específico, hay que tener presente que en la cadena de suministro agrícola y alimentario participan una diversidad de operadores en el conjunto de las fases que integran la concepción de la cadena de distribución "de la granja a la mesa" ${ }^{12}$. Es decir, los agentes de producción, transformación, comercialización, distribución y venta al por menor de los mencionados productos. En consecuencia, las actuaciones comerciales desleales que se ejercen en dicha cadena despliegan sus efectos adversos de manera directa en los productores agrícolas y sus organizaciones (proveedores) e, indirectamente, afectan al conjunto de los productores primarios. Razón que ha justificado la intervención de la Comisión Europea en esta materia de un modo singular, a fin de amparar los legítimos intereses económicos de la totalidad de los sujetos que operan en el mercado agrícola y alimentario.

10. Art. 38 de la Constitución Española.

11. Art. 51 de la Constitución Española.

12. Considerandos 5 a 7 de la Directiva (UE) 2019/633. 


\section{El mercado agroalimentario y las conductas comerciales desleales. Ámbito comunitario}

\section{A. Referencias precedentes}

Las singularidades del mercado de productos agroalimentarios imponen la necesaria identificación de los presupuestos proporcionados por el ordenamiento para ofrecer un nivel adecuado de competencia en beneficio no sólo de su correcto funcionamiento, sino de manera especial de la protección y garantía de los que participan en dicho mercado en un sentido amplio. Esto es, en relación con el conjunto de los operadores que intervienen en la figurada cadena de distribución que vincula "el campo con la mesa" como dispone el legislador comunitario (distribuidores, fabricantes, agricultores, mayoristas, consumidores, entre otros).

La reglamentación europea de las prácticas comerciales desleales en el mercado único está prevista, en líneas generales, en la Directiva (UE) 2005/29/CE relativa a las prácticas comerciales desleales de las empresas en sus relaciones con los consumidores en el mercado interior ${ }^{13}$. Esta norma se ocupa de aproximar las regulaciones de los Estados miembros sobre las conductas comerciales desleales que suponen un perjuicio para los intereses económicos de los consumidores en cuanto a las transacciones relacionadas con los productos y, de modo indirecto, para los competidores legítimos que operan de forma lícita en el mercado. Y ello a fin de garantizar la competencia leal en el ámbito coordinado por las previsiones del propio tenor de la norma. No obstante, su ámbito de aplicación no es extensible a los comportamientos comerciales desleales y a las prácticas publicitarias que perjudican sólo a los intereses económicos de los competidores o, en su caso, que se refieren a transacciones realizadas entre comerciantes. Respecto de las prácticas publicitarias, habrá de atenderse

13. Directiva 2005/29/CE, del Parlamento Europeo y del Consejo, de 11 de mayo, relativa a las prácticas comerciales desleales de las empresas en sus relaciones con los consumidores en el mercado interior, que modifica la Directiva 84/450/CEE, las Directivas 97/7/CE, 98/27/CE y 2002/65/CE y el Reglamento (CE) 2006/2004 (Directiva sobre las prácticas comerciales desleales. DOUE L149, de 11 de junio). Para ampliar esta materia, vid. MASSAGUER FUENTES, J.: El nuevo Derecho contra la competencia desleal. La Directiva 2005/29/CE sobre las Prácticas Comerciales Desleales, Thomson Civitas, Cizur Menor, 2006; MASSAGUER FUENTES, J.: Comentario a la Ley de Competencia Desleal, Civitas, Madrid, 1999; y TATO PLAZA, A., FERNÁNDEZ CARBALLO- CALERO, P. \& HERRERA PETRUS, C.: La reforma de la ley de competencia desleal, Editorial La Ley, Madrid, 2010, passim. Así como, la Directiva (UE) 2011/83, del Parlamento Europeo y del Consejo, de 25 de octubre de 2011, por la que se modifican la Directiva 93/13/CEE del Consejo y la Directiva 1999/44/CE del Parlamento Europeo y del Consejo y se derogan la Directiva 85/577/CEE del Consejo y la Directiva 97/7/CE del Parlamento Europeo y del Consejo, sobre los derechos de los consumidores (DOUE L304, de 22 de noviembre); y la Directiva 2009/22/CE, del Parlamento Europeo y del Consejo, de 23 de abril de 2009, relativa a las acciones de cesación en materia de protección de los intereses de los consumidores (DOUE L110, de 1 de mayo). 
a lo dispuesto en la Directiva (UE) 2006/114/CE sobre publicidad engañosa y publicidad comparativa ${ }^{14}$, la cual incluye la referencia a la tutela de los comerciantes o competidores frente a los efectos de las conductas de publicidad engańosa y los principios generales uniformes que hacen que la comparación promocional resulte lícita. Excluyendo las referencias particulares sobre la protección de los consumidores.

Sin embargo, el inconveniente principal se mantenía en cuanto a la ordenación de las prácticas comerciales contrarias a la leal competencia que se sucedían entre los participantes de concretos mercados específicos, como el agroalimentario, en el que confluyen una heterogeneidad de operadores que no se sitúan en el mismo plano desde la perspectiva económica y contractual. Circunstancias que preocuparon a la Comisión Europea y que le hicieron evaluar la distinta posición ostentada en el mercado de productos agrícolas y alimentarios de las pequeñas y medianas empresas, de los productores y de los agricultores. El resultado fue considerar que estos sujetos conforman el sector vulnerable de la cadena de valor y, en parte, no encuentran tutela en el ámbito de protección conferido por los textos normativos anteriormente indicados. Por lo que se dedujo la necesidad de aprobar una norma centrada en la regulación de los comportamientos comerciales que se llevan a cabo entre las dispares posiciones de los operadores en la cadena agroalimentaria (la Directiva (UE) 2019/633). La conclusión del mencionado texto jurídico derivó de la superación de una serie de iniciativas de diversa naturaleza en las que tanto la Comisión, como el Parlamento Europeo pusieron de manifiesto la carencia de tutela para este sector del mercado.

La actuación de la Comisión sobre el particular se vio reflejada, en primer término, en el interés por la mejora del funcionamiento de la cadena europea de abastecimiento alimentario ${ }^{15}$ que engloba importantes sectores (agrícola, la industria de transformación y el sector de la distribución). Así, se trata de conseguir que la cadena alimentaria resulte más eficiente mediante la transparencia en los precios de los diferentes eslabones que la conforman y la mejora de las relaciones comerciales entre los agentes participantes, pues se detectan divergencias en las relaciones contractuales que se concluyen en razón del diverso poder de negociación en cada caso. A este respecto, básicamente, la Comisión Europea propuso el fomento de relaciones

14. Directiva 2006/114/CE, del Parlamento Europeo y del Consejo, de 12 de diciembre, sobre publicidad engañosa y publicidad comparativa (DOUE L376, de 27 de diciembre). La aprobación de dicha norma pretendió la compilación de los anteriores textos jurídicos que regulaban la materia (en concreto, la Directiva 84/450/CEE del Consejo, relativa a la aproximación de las disposiciones legales, reglamentarias y administrativas de los Estados miembros en materia de publicidad engañosa y sus sucesivas modificaciones).

15. Comunicación de la Comisión Europea de 28 de octubre de 2009 sobre la mejora del funcionamiento de la cadena alimentaria en Europa (COM (2009)591 final, de 28 de octubre). 
sostenibles y fundadas en principios de mercado, junto a la integración del mercado interior de alimentos y la competitividad de todos los agentes de la cadena de valor, y su actuación en cuanto a las prácticas contractuales desleales generadas por las asimetrías en la capacidad de negociación y en lo que concierne a la transparencia sobre la vigilancia de los precios de los alimentos.

En segundo lugar, la Comisión Europea se cuestionó el modo de superar los comportamientos comerciales desleales en la cadena de suministro alimentario entre empresas $^{16}$. En este planteamiento la pretensión fue localizar mecanismos para mejorar la tutela de los pequeños productores de alimentos y minoristas contra las prácticas desleales del resto de operadores económicos y, de modo particular, en los casos en los que el distinto poder de negociación entre ellos se traduce en desequilibrios que dan lugar a prácticas comerciales desleales ${ }^{17}$. La superación de esta situación lleva a la Comisión a plantear tanto el apoyo a los principios normativos comunitarios en relación con las buenas prácticas y, en consecuencia, la aplicación de las normas mínimas como mecanismo disuasorio frente a las prácticas comerciales desleales en la cadena de suministro, cuanto el apoyo a la Iniciativa de la Cadena de Suministro voluntaria sobre el oportunismo de los códigos de conducta de carácter potestativo. Esto es, la conclusión de la Iniciativa de la Cadena de Suministro partiendo de los principios de buenas prácticas en las Relaciones verticales en la cadena de suministro alimentario concertados con las organizaciones que representaban los intereses del conjunto de los agentes de la caden $\mathrm{a}^{18}$ y el documento Marco para la aplicación y el cumplimiento de los mencionados principios (Foro de Alto Nivel sobre la Mejora del Funcionamiento de la Cadena Alimentaria) ${ }^{19}$.

16. Comunicación de la Comisión Europea de 15 de julio de 2014 sobre cómo hacer frente a las prácticas comerciales desleales en la cadena de suministro alimentario entre empresas (COM (2014) 472 final, de 15 de julio).

17. Tales como lo son: impedir que consten por escrito cláusulas comerciales esenciales, modificaciones unilaterales y de carácter retroactivo del precio de los productos, la transferencia de riesgos injustificados o desproporcionados a una de las partes de la relación contractual, la alteración intencionada de los plazos de entrega o recepción a fin de conseguir un beneficio injustificado, o la conclusión unilateral de una relación comercial al margen del previo aviso y sin un motivo objetivamente justo.

18. Iniciativa de la cadena de suministro-Supply Chain Initiative, SCI-. Libro Verde sobre prácticas comerciales desleales en la cadena de suministro alimentario y no alimentario entre empresas en Europa (COM 2013- 37 final), y 2nd Annual Report (enero 2016, disponible en el recurso electrónico:

https://supplychaininitiative.eu/sites/default/files/annual_report_02_finale_0.pdf).

19. Decisión de la Comisión Europea de 30 de julio de 2010 por la que se instituye el Foro de Alto Nivel sobre la Mejora del Funcionamiento de la Cadena Alimentaria (DOUE de 3 de agosto de 2020). En 2015, la Comisión en su Decisión de 1 de junio acordó la renovación del mismo (DOUE C179, de 2 de junio). 
Aun cuando los referidos planteamientos se centran en la repercusión de las prácticas comerciales desleales entre empresas en el funcionamiento de la cadena de suministro alimentario, la Comisión Europea emite con posterioridad un Informe al Parlamento en el que se ocupa de la evaluación de los instrumentos existentes para resolver las cuestiones generadas por los comportamientos comerciales desleales ${ }^{20}$, a saber: los marcos reguladores y de garantía de cumplimiento por parte de los Estados miembros y los efectos de la reseñada Iniciativa de la Cadena de Suministro y de las plataformas de ésta que se han creado internamente en cada uno de los Estados miembros. Las deducciones que se hacen, en ambos sentidos, se concretan en el reconocimiento del avance en la regulación por parte de los ordenamientos nacionales y su eficacia contra las prácticas comerciales desleales, pero se detecta la necesidad de mejorar la Iniciativa de la Cadena de Suministro voluntaria para incrementar su credibilidad y eficacia.

También interesa poner de relieve la creación por parte de la Comisión Europea del Grupo Operativo sobre Mercados Agrícolas $(A M T F)^{21}$, al objeto de evaluar el papel de los agricultores en el conjunto de la cadena de suministro de alimentos y hacer recomendaciones para corregir las imperfecciones del mercado y la mayor volatilidad de los precios establecidos en el sector.

En cuanto a las iniciativas del Parlamento Europeo, cabe partir de la Resolución sobre un mercado minorista más eficaz y justo que se funda en los siguientes pilares esenciales $^{22}$ : el fomento de la competitividad, el crecimiento y el empleo; la eliminación de los impedimentos de la libre circulación de bienes y servicios; la ampliación del acceso a los mercados para las empresas y los consumidores; la mejora de la eficacia y del consumo sostenible; y las conductas contractuales y comerciales en las relaciones de empresa a empresa $(B \mho B)$. En este sentido, se apuesta por el correcto funcionamiento del mercado minorista mediante una competencia libre y justa, la libertad de contratación y una aplicación correcta y efectiva de la legislación.

Actualmente, ha de consultarse el High Level Forum for a Better Functioning Food Supply Chain. Final report. Document date: 21 June 2019- Publication date: 24 June 2019 (disponible en el recurso electrónico: https://ec.europa.eu/docsroom/documents/36045).

20. Informe de la Comisión de 29 de enero de 2016 sobre las prácticas comerciales desleales en la cadena de suministro alimentario entre empresas (COM (2016) 32 final, de 29 de enero). Puede consultarse, también, el Informe sobre prácticas comerciales desleales en la cadena de suministro alimentario (2015/2065(INI) de la Comisión de Mercado Interior y Protección del Consumidor, de 4 de mayo 2016.

21. En 2016 se creó el Grupo Operativo sobre Mercados Agrícolas $(A M T F)$ a fin de evaluar el papel de los agricultores en el conjunto de la cadena de suministro de alimentos y elaborar recomendaciones al respecto.

22. Resolución del Parlamento Europeo, de 5 de julio de 2011, sobre un mercado minorista más eficaz y más justo (2010/2109(INI). DOUE C33, de 5 de febrero 2013). 
A esta iniciativa le siguió la Resolución sobre los desequilibrios en la cadena alimentaria $^{23}$, en cuyo caso el Parlamento Europeo puso de relieve las asimetrías en el poder de negociación entre los minoristas de gran tamańo y los productores y otros proveedores. Estas divergencias se reflejan en ciertas prácticas comerciales desleales concernientes a los retrasos en los pagos, las modificaciones contractuales unilaterales, la inserción de cláusulas abusivas, o la falta de información sobre los precios, entre otras. Los efectos del diverso poder de negociación en las transacciones, el incremento de los costes de producción y la imposibilidad de recuperarlos en la cadena alimentaria implican un perjuicio directo a las explotaciones agrícolas, por lo que se aboga por el fomento de las relaciones comerciales equilibradas a fin de que ello redunde en la mejora del funcionamiento de la cadena y la competitividad. En relación con esta Resolución se aprueba otra cuyo contenido se centra en las prácticas comerciales desleales en la cadena de suministro alimentario ${ }^{24}$ y en la que el Parlamento destaca el menoscabo que suponen las prácticas desleales a nivel económico (tanto en el sector alimentario, como en la automoción o en el textil) y los "agravios comparativos" en la cadena de suministro de alimentos. Aspectos que afectan no sólo al desarrollo del mercado interior y su adecuado funcionamiento, sino también a los propios consumidores que forman parte de dicho mercado. En este sentido, el Parlamento Europeo propuso a la Comisión que presentara una propuesta de marco jurídico sobre las prácticas comerciales desleales, la cual se materializó en la Propuesta Unfair trading practices in the food chain de $2018^{25}$ que partió de la pionera Ley española para la mejora de la cadena alimentaria ${ }^{26}$. La pretensión principal de su tenor no se focaliza en

23. Resolución del Parlamento Europeo, de 19 de enero de 2012, sobre los desequilibrios en la cadena alimentaria (P7_TA (2012)0012. DOUE C227, de 6 de agosto 2013).

24. Resolución del Parlamento Europeo, de 7 de junio de 2016, sobre prácticas comerciales desleales en la cadena de suministro alimentario (DOUE C86, de 6 de marzo de 2018). Véanse también las Conclusiones alcanzadas por el Consejo Europeo en este sentido, Strengthening farmers' position in the food supply chain and tackling unfair trading practices, 12 de diciembre de 2016, Council at its 3509th (disponibles en el recurso electrónico: https://www.consilium.europa.eu/media/22604/st15508en16.pdf).

25. Bruselas, 12 de abril de 2018, SWD (2018) 92 final.

26. Ley $12 / 2013$, de 2 de agosto, de medidas para mejorar el funcionamiento de la cadena alimentaria (BOE núm. 185, de 3 de agosto). Para ampliar esta información, vid. VICIANO PASTOR, J. (dir.) \& CORBERÁ MARTÍNEZ, J.M. (coord.): Retos en el Sector Agroalimentario Valenciano en el Siglo XXI, Tirant lo Blanch, València, 2019; CAZORLA GONZÁLEZ, M.J. \& BARDERA BALDRICH, M.M.: "ANÁLISIS DE LAS RELACIONES COMERCIALES Y DE COMPETENCIA EN LA CADENA DE SUMINISTRO ALIMENTARIA", Revista de derecho agrario y alimentario, no 36(76), 2020, pp. 7-48; CRUZ ROCHE, I. \& PALMA FERNÁNDEZ, J.L.: "La Ley de la Cadena Alimentaria". En: Distribución comercial: todas las claves de la Distribución desveladas por las grandes compañias del sector (dirs. MUÑOZ DEL CAZ, E. \& ORTEGA BURGOS, E.), Editorial Aranzadi, Cizur Menor, 2017, pp. 1277-1288; MAUDES GUTIÉRREZ, A. \& 
la tutela de los intereses de los consumidores de modo directo, cuánto en la igualdad de oportunidades de las pequeñas y medianas empresas alimentarias y agrícolas, los productores y los agricultores ${ }^{27}$. Las actuaciones desleales que tratan de mitigarse con esta Propuesta son las prácticas comerciales que infringen los principios de buena fe y comercio justo en el mercado, ya que son impuestas de manera unilateral por un socio y el poder de negociación de la contraparte queda limitado a la simple aceptación del contenido establecido. De un lado, la Propuesta incluye un listado o elenco de prácticas comerciales prohibidas cuando se ejercen entre proveedores y compradores; de otro, un conjunto de reglas mínimas que de modo necesario hay que observar en las transacciones comerciales; y, por último, se prevé la precisa coordinación entre las autoridades de control u órganos públicos independientes con capacidad de sancionar, iniciar una investigación de oficio y recibir las denuncias presentadas por los particulares. Si bien, pese a que esta Propuesta fomenta el incremento de la transparencia del mercado europeo y la limitación de comportamientos comerciales prohibidos, quedan al margen las prácticas comerciales desleales entre empresas u operadores económicos y tampoco se precisada su aplicación a las conductas desleales que se produzcan en las transacciones comerciales que afecten a varios Estados miembros de la UE.

En lo que hace a la perspectiva objetiva se distinguen dos tipos de prácticas desleales y sus efectos jurídicos: las que están prohibidas en todo caso (demoras en los pagos de productos perecederos, las cancelaciones de última hora, las modificaciones unilaterales o retroactivas de los contratos y que se obligue al proveedor a hacerse cargo de los gastos de los productos perdidos) y los comportamientos que serán legítimos en tanto que estén sometidos a un acuerdo previo entre las partes. La falta de observancia de los presupuestos contenidos en la Propuesta da lugar a la correspondiente inspección por parte de la autoridad pública estatal con competencia para hacer cumplir estas prohibiciones y, si procede, la imposición de la sanción correspondiente y aplicable según el caso.

SILOS RIBAS, M.: "Valoración de la ley de la cadena alimentaria desde la perspectiva de la promoción de la competencia". En: Derecho de la competencia y gran distribución (coords. CACHAFEIRO GARCÍA, F., GARCÍA PÉREZ, R. \& LÓPEZ-SUÁREZ, M.A.), Editorial Aranzadi, Cizur Menor, 2016, pp. 249-268; y VICIANO PASTOR, J.: "Algunas reflexiones (críticas) sobre la Ley 12/2013 de la cadena alimentaria de medidas para mejorar el funcionamiento de la cadena alimentaria". En: Estudios sobre el régimen jurídico de la cadena de distribución agroalimentaria, (dirs. GONZÁLEZ CASTILLA, F. \& RUIZ PERIS, J.L.), Marcial Pons, Ediciones Jurídicas y Sociales, Madrid, 2016, pp. 171-182.

27. La referida Propuesta Unfair trading practices in the food chain (12 de abril de 2018) que deriva de la Resolución del Parlamento Europeo adoptada en junio de 2016, en la que se invitaba a la Comisión a presentar una propuesta para un marco a escala de la UE relativo a las prácticas comerciales desleales. Vid. SCHEBESTA, H., VERDONK, T., PURNHAGEN, K.P. \& KEIRSBILCK, B.: "Unfair Trading Practices in the Food Supply Chain: Regulating Right?”, European Journal of Risk Regulation (EJRR), no 9(4), 2018, pp. 690-700. 


\section{B. La regulación de las prácticas comerciales desleales en la cadena de suministro agrícola y alimentario}

Las directrices expuestas, partiendo de la vulnerabilidad de las pequeñas y medianas empresas agrícolas y alimentarias en la cadena de suministro, fueron el sustento de la iniciativa legislativa de la Comisión Europea que trata de prohibir las prácticas comerciales desleales en la misma, al objeto de conseguir la igualdad de oportunidades de todos los operadores que participan en dicho mercado. Nos referimos a la regulación de los comportamientos comerciales recogidos en la Directiva (UE) 2019/633, sobre las prácticas comerciales desleales en las relaciones entre empresas en la cadena de suministro agrícola y alimentario ${ }^{28}$. La norma atiende a los actos que se ejercen en las relaciones comerciales en el ámbito agrario entre los proveedore ${ }^{29} \mathrm{y}$ los compradores (personas físicas o jurídicas o un grupo de ellas, o autoridad pública) en las que se perciben diferencias del poder de negociación de las partes. Y éstas se corresponden con la dependencia económica del proveedor respecto del distribuidor $^{30}$. Esta norma pretende limitar las prácticas comerciales contrarias a la lealtad en el mercado agroalimentario en cuanto que infringen los principios de buena $\mathrm{fe}$ y comercio justo en el mismo, al ser impuestas de manera unilateral por una de las partes contractuales.

Los temas que, a nuestro modo de ver, merecen una especial atención en el texto normativo son, básicamente, el ámbito subjetivo de tutela que se ofrece, el contenido objetivo en cuanto al conjunto mínimo o listado de prácticas prohibidas por califi-

28. Vid. AMAT LLOMBART, P.: "Contratación de productos agrarios en la cadena alimentaria y prácticas comerciales desleales a propósito de la transposición de la Directiva 2019/633”, Revista de derecho agrario y alimentario, no 36(77), 2020, pp. 7-67; GARCÍA VIDAL, A.: "Prácticas comerciales desleales en la cadena de suministro agrícola y alimentario. Impacto de la Directiva (UE) 2019/633 en el Derecho español”, GA_P. Análisis, 2019, pp. 1-8; GONZÁLEZ CASTILLA, F.: "La represión de las prácticas comerciales desleales en la cadena agroalimentaria europea”. En: Estudios sobre el régimen jurídico de la cadena de distribución agroalimentaria, (dirs. GONZÁLEZ CASTILLA, F. \& RUIZ PERIS, J.I.), Marcial Pons, Ediciones Jurídicas y Sociales, Madrid, 2016, pp. 183-198; y RODRÍGUEZ CACHÓN, T.: "Relaciones contractuales en la cadena alimentaria: análisis a la luz de la nueva regulación”, Revista de Derecho Civil (RDC), no 5(1), 2018, pp. 191-227.

29. Esto es, cualquier tipo de persona o grupo de personas, incluidas las organizaciones de productores, las organizaciones de proveedores y las asociaciones de tales organizaciones.

30. Cdo 9 de la Directiva (UE) 2019/633, en concreto: (...) Las prácticas comerciales desleales son perjudiciales, en particular para las pequeñas y medianas empresas (pymes), de la cadena de suministro agricola y alimentario. Las empresas más grandes que las pymes pero con una volumen de negocios anual inferior a 350000000 EUR, también deben ser protegidas contra las prácticas comerciales desleales, para evitar que el coste de dichas prácticas se traslade a los productores agricolas. Las consecuencias en cascada sobre los productores agricolas parecen ser particularmente significativas para las empresas con un volumen de negocios anual de hasta 350000000 EUR (...) 
carse de desleales en lo que concierne a la cadena de suministro ${ }^{31}$ y las consideraciones acerca del procedimiento de reclamación.

La lectura detenida del texto que nos ocupa permite señalar que el ámbito subjetivo de protección se refiere a cualquier agente involucrado en la cadena de suministro de alimentos, pero con niveles de protección diferenciados según los tramos de facturación, lo que consiente la división de productores hasta en cinco categorías en función de sus ingresos. Nos referimos a productores con una facturación anual de menos de 350 millones de euros y dividiéndose, a su vez, en minoristas, procesadores de alimentos, mayoristas, cooperativas u organizaciones de productores e, incluso, un solo productor.

Desde el punto de vista del contenido objetivo de tutela ${ }^{32}$, se recoge un listado de mínimos en lo que hace a las prácticas prohibidas susceptibles de calificarse de desleales dentro de la cadena de suministro. Entre ellas destacan las que a continuación se relacionan: el retraso en el pago de productos ya entregados, la cancelación unilateral retardada de un pedido o su modificación retroactiva, el rechazo del comprador a firmar un contrato por escrito con el proveedor, o el uso incorrecto de información confidencial. En igual sentido, la amenaza a los productores con dejar de consumir sus productos o retrasar los pagos si presentan alguna reclamación, o la solicitud a los agricultores de compensaciones económicas en el supuesto de deterioro o pérdida de los productos una vez entregados, a menos que ello se deba a una negligencia por parte del proveedor.

Junto a los comportamientos reseñados, las previsiones normativas recogen un listado de seis prácticas comerciales específicas que de manera expresa se prohíben; a saber: la devolución de los artículos no vendidos sin haberlos abonado o su eliminación, obligar a los proveedores a pagar por publicitar, vender o catalogar, almacenar o exponer sus productos, o la imposición de costes de descuento al proveedor. Sin embargo, la limitación de estos comportamientos no se entiende con carácter absoluto, sino relativo, ya que será posible su ejecución si las partes lo hubieran acor-

31. Art. 3 de la Directiva (UE) 2019/633. Sobre el tenor de la norma comunitaria, pueden consultarse los siguientes trabajos: GONZÁLEZ CASTILLA, F. \& RUIZ PERIS, J.L. (dirs.): Estudios sobre el régimen juridico de la cadena de distribución agroalimentaria, Marcial Pons, Ediciones Jurídicas y Sociales, Madrid, 2016, passim; CACHAFEIRO GARCÍA, F., GARCÍA PÉREZ, R. \& LÓPEZ-SUÁREZ, M.A. (coords.): Derecho de la competencia y gran distribución, Editorial Aranzadi, Cizur Menor, 2016, passim; ARIAS VARONA, F.J.: "La armonización europea de la regulación de la cadena alimentaria", La Ley mercantil, no 60, 2019; CRESPO PEREIRA, D. \& ARIAS VARONA, F.J.: "Hacia una regulación de la cadena alimentaria", Gaceta jurídica de la Unión Europea y de la competencia, no 33, 2013, pp. 9-18; y CRUZ ROCHE, I. \& PALMA FERNÁNDEZ, J.L., op. cit., pp. 1277-1288. 
dado previamente de manera clara y sin que pueda estimarse la ambigüedad en el contenido del contrato o en cualquier relación contractual posterior que se concluya entre el proveedor y el comprador. No obstante, se trata de una lista indicativa y de contenido mínimo de actuaciones comerciales, lo que hace posible que los Estados miembros puedan ampliarla en sus regulaciones internas.

A lo referido se suman unas disposiciones tendentes a establecer el control del cumplimiento de las limitaciones expuestas y la coordinación entre las autoridades encargadas del mismo. Haciendo una especial mención a la resolución alternativa de litigios de carácter voluntario, es decir el recurso a la mediación o a la aplicación del arbitraje como formas de solventar las posibles controversias suscitadas. Se trata del reconocimiento de un régimen de protección más accesible, de menor coste y adaptado a las circunstancias concretas de cada supuesto particular, por lo que los mecanismos alternativos de resolución de conflictos serán una prioridad en este ámbito. Por consiguiente, el productor tiene reconocida la facultad de reclamar en el país de origen de su actividad, aun cuando la práctica comercial cuestionada se lleve a cabo en otro Estado miembro de la UE, correspondiendo a las autoridades nacionales la gestión de las quejas y/o reclamaciones y su resolución o, si procede, el inicio de la investigación que sea procedente de oficio. Aunque, también, se determina como propuesta la opción de acudir a los indicados mecanismos alternativos de resolución de conflictos.

\section{Régimen normativo interno sobre los comportamientos desleales. Especial referencia al sector agroalimentario}

\section{A. Indicaciones sobre las previsiones generales que regulan la competencia en el mercado y el sector agroalimentario}

En el ordenamiento interno resulta esencial prestar atención a dos normas que se han ocupado de la tutela de la competencia en el mercado y la organización eficiente del mismo en beneficio del conjunto de sujetos que participan en él. Esta protección se refleja en la defensa contra los actos realizados en el mercado y dirigidos a impedir que la competencia funcione en plenitud, en cuyo caso nos referimos a la Ley 15/2007 de Defensa de la Competencia (LDC) y al Real Decreto 261/2008 por el que se aprueba el Reglamento de Defensa de la Competencia ${ }^{33}$, textos básicos res- 
pecto al modelo de organización económica. Así como, en la defensa contra los actos que perturban la funcionalidad de la competencia en el mercado, pero sin impedirla. Esto es, la Ley 3/1991 sobre Competencia Desleal (LCD) ${ }^{34}$.

No obstante, las disposiciones jurídicas contenidas en la Directiva 2005/29/CE relativa a las prácticas comerciales desleales de las empresas en sus relaciones con los consumidores en el mercado interior y la Directiva 2006/114/CE sobre publicidad engañosa y publicidad comparativa, fueron objeto de transposición en el ordenamiento interno con la aprobación de la Ley 29/2009 $9^{35}$. Norma que supuso la modificación del régimen legal de la competencia desleal y de la publicidad para la mejora de la tutela y garantía de los operadores económicos que participan en el mercado en general y de los intereses de los consumidores y usuarios en particular. En consecuencia, el texto referido conllevó la alteración del contenido relativo al régimen jurídico de las conductas y comportamientos desleales ${ }^{36}$ y el de la actividad publicitaria ${ }^{37}$, afectando no sólo a la LCD, sino también a la regulación de la defensa de los consumidores y usuarios, a la ordenación del comercio minorista y a la Ley General de

Orgánico de la Comisión Nacional de los Mercados y la Competencia (BOE núm. 209, de 31 de agosto) y la Ley 1/2002, de 21 de febrero, de coordinación de las Competencias del Estado y de las Comunidades Autónomas en materia de Defensa de la Competencia (BOE núm. 46, de 22 de febrero). En el ámbito comunitario, junto a diversas Comunicaciones y Directrices, como es sabido, la defensa de la competencia se ha materializado en los artículos 101 a 109 del TFUE, el Reglamento (CE) 1/2003 del Consejo, de 16 de diciembre 2002, relativo a la aplicación de las normas sobre competencia (DOUE L1, de 4 de enero) y el Reglamento (CE) 139/2004 del Consejo, de 20 de enero, sobre el control de las concentraciones (DOUE L24, de 29 de enero. Modificado por el Reglamento 519/2013, de 21 de febrero).

34. Ley 3/1991, de 10 de enero, de Competencia Desleal (BOE núm. 10, de 11 de enero).

35. Ley 29/2009, de 30 de diciembre, por la que se modifica el régimen legal de la competencia desleal y de la publicidad para la mejora de la protección de los consumidores y usuarios (BOE núm. 315, de 31 de diciembre). Vid. ARMIJO CHÁVARRI, E. (coord.): Análisis de la reforma del régimen legal de la competencia desleal y la publicidad llevada a cabo por la Ley 29/2009, de 30 de diciembre, Editorial La Ley, Madrid, 2011; BENEYTO, K. (dir.) \& ARMENGOT VILAPLANA, A. (coord.): Actos de Competencia Deslealy su Tratamiento Procesal, Tirant lo Blanch, València, 2020; MASSAGUER FUENTES, J.: El nuevo..., passim; MASSAGUER FUENTES, J.: Comentario..., passim; y TATO PLAZA, A., FERNÁNDEZ CARBALLO-CALERO, P. \& HERRERA PETRUS, C., op. cit., passim.

36. Arts. 5 a 17 de la LCD: actos de engaño, de confusión, de denigración, la imitación, la explotación de la reputación ajena, la violación de secretos, la inducción a la infracción contractual, la violación de normas, la discriminación y dependencia económica, la venta a pérdida y las prácticas agresivas. Sobre ello, pueden consultarse, entre otros: MASSAGUER FUENTES, J.: El nuevo..., passim; TATO PLAZA, A., FERNÁNDEZ CARBALlO-CALERO, P. \& HERRERA PETRUS, C., op.cit., passim.; y VÁZQUEZ RUANO, T.: "Aspectos de competencia en la comercialización de productos agroalimentarios", Actas de derecho industrialy derecho de autor (ADI), no 38, 2017-2018, pp. 423-440.

37. Art. 18 de la LCD. Sobre el particular, vid. TATO PLAZA, A.: "La reforma de la Ley General de Publicidad", Revista de Derecho de la Competencia y la Distribución (RCD), nº 7, 2010, pp. 141-154. 
(pp. 199-240)

Publicidad ${ }^{38}$, fundamentalmente. A este respecto, se ha incluido con esta norma una regulación unitaria de la deslealtad de los actos de engaño y de las prácticas agresivas en el mercado. A lo que se añade el régimen de la publicidad contraria a Derecho, al reconocer de forma expresa como práctica desleal la publicidad ilícita. Y, también, se ha establecido un sistema de acciones judiciales homogéneo frente a los comportamientos desleales que se llevan a cabo en el mercado y que perjudican los intereses económicos de los participantes en el mismo ${ }^{39}$.

Junto a las previsiones generales propias del ámbito comercial y publicitario, en el mercado de productos agroalimentarios se hace preciso atender otros presupuestos relacionados con la propia especialidad de dicho sector. En particular, en cuanto a las declaraciones nutricionales, el etiquetado de los productos, la calidad de los alimentos y la organización común de mercados de los productos agrarios ${ }^{40}$. En el ámbito nacional, y sin ánimo de exhaustividad, puede referirse el Real Decreto 1808/1991 por el que se regulan las menciones o marcas que permiten identificar el lote al que pertenece un producto alimenticio ${ }^{41}$, el Real Decreto $1334 / 1999$ respecto a la Norma general de etiquetado, presentación y publicidad de los productos alimenticios ${ }^{42}$, el Real Decreto 1801/2008 por el que se establecen normas relativas a las cantidades

38. Ley 29/2009 ha supuesto la modificación de los siguientes textos normativos: Real Decreto Legislativo 1/2007, de 16 de noviembre, por el que se aprueba el texto refundido de la Ley General para la Defensa de los Consumidores y Usuarios y otras leyes complementarias (BOE núm. 287, de 30 de noviembre, en adelante TRLDCU); la Ley 7/1996, de 15 de enero, de Ordenación del Comercio Minorista (BOE núm. 15, de 17 de enero, en adelante LOCM); la Ley 34/1988, de 11 de noviembre, General de Publicidad (BOE núm. 274, de 15 de noviembre, en adelante LGP); y la LCD. También cabe hacer alusión a otras normas que afectan a la información que se difunde en el mercado, como la Ley 17/2001, de 7 de diciembre, de Marcas (BOE núm. 294, de 8 de diciembre, en adelante LM).

39. Arts. 32 a 36 de la LCD.

40. Reglamento (CE) 1924/2006 del Parlamento Europeo y del Consejo, de 20 de diciembre de 2006, relativo a las declaraciones nutricionales y de propiedades saludables en los alimentos (DOUE L404, de 30 de diciembre); Reglamento (CE) 834/2007 del Consejo, de 28 de junio de 2007, sobre producción y etiquetado de los productos ecológicos (DOUE L189, de 20 de julio); Reglamento (UE) 1169/2011 del Parlamento Europeo y del Consejo, de 25 de octubre de 2011, sobre la información alimentaria facilitada al consumidor (DOUE L304, de 22 de noviembre); Reglamento (CE) 1151/2012 del Parlamento Europeo y del Consejo, de 21 de noviembre, sobre los regímenes de calidad de los productos agrícolas y alimenticios (DOUE L343, de 14 de diciembre); Reglamento (CE) 1308/2013 del Parlamento Europeo y del Consejo, de 17 de diciembre, por el que se crea la organización común de mercados de los productos agrarios (DOUE L347, de 20 de diciembre).

41. Real Decreto 1808/1991, de 13 de diciembre, por el que se regulan las menciones o marcas que permiten identificar el lote al que pertenece un producto alimenticio (BOE núm. 308, de 25 de diciembre).

42. Real Decreto 1334/1999, de 31 de julio, por el que se aprueba la norma general de etiquetado, presentación y publicidad de los productos alimenticios (BOE núm. 202, de 24 de agosto). 
nominales para productos envasados y al control de su contenido efectivo ${ }^{43}$, el Real Decreto 126/2015 en cuanto a la información alimentaria de los alimentos que se presenten sin envasar para la venta al consumidor final y a las colectividades, de los envasados en los lugares de venta a petición del comprador y de los envasados por los titulares del comercio al por menor ${ }^{44}$ y la Ley 28/2015 para la defensa de la calidad alimentaria ${ }^{45}$.

Si bien, el estudio de los mecanismos de protección o tutela de los intereses de los distintos sectores de la cadena de suministro de productos agroalimentarios requiere centrar la atención en la garantía de los operadores de menor tamańo que participan en la cadena de valor y en la mejora del funcionamiento de la misma. En concreto, respecto a determinados comportamientos que realizan los operadores económicos en el ámbito agroalimentario, a fin de poder valorar si suponen un perjuicio para el juego de la leal competencia en este específico mercado. Nos referimos, a las previsiones contenidas en la Ley 12/2013 de medidas para mejorar el funcionamiento de la cadena alimentaria ${ }^{46}$.

En la materia que nos ocupa, asimismo, cabe hacer mención a las disposiciones de la Ley 13/2013 de fomento de la integración de cooperativas y de otras entidades asociativas de carácter agroalimentario ${ }^{47}$. De modo particular, su contenido tiene como objetivo esencial la garantía del sector primario como parte débil de la

43. Real Decreto 1801/2008, de 3 de noviembre, por el que se establecen normas relativas a las cantidades nominales para productos envasados y al control de su contenido efectivo (BOE núm. 266, de 4 de noviembre).

44. Real Decreto 126/2015, de 27 de febrero, por el que se aprueba la norma general relativa a la información alimentaria de los alimentos que se presenten sin envasar para la venta al consumidor final y a las colectividades, de los envasados en los lugares de venta a petición del comprador, y de los envasados por los titulares del comercio al por menor (BOE núm. 54, de 4 de marzo).

45. Ley 28/2015, de 30 de julio, para la defensa de la calidad alimentaria (BOE núm. 182, de 31 de julio).

46. Puede consultarse también el Real Decreto 64/2015, de 6 de febrero, por el que se desarrolla parcialmente la Ley 12/2013, y se modifica el Reglamento de la Ley 38/1994, reguladora de las organizaciones interprofesionales agroalimentarias, aprobado por Real Decreto 705/1997, de 16 de mayo (BOE núm. 33, de 7 de febrero). Vid. ARAUJO BOYD, M. \& FERRER VIEYRA, E.: "La Ley de medidas para mejorar el funcionamiento de la cadena alimentaria. Una visión desde el derecho de la competencia”, Gaceta jurídica de la Unión Europea y de la competencia, no 35, 2013, pp. 16-21; CAZORLA GONZÁLEZ, M.J. \& BARDERA BALDRICH, M.M., op. cit., pp. 7-48; CRUZ ROCHE, I. \& PALMA FERNÁNDEZ, J.L., op.cit., pp. 1277-1288; MAUDES GUTIÉRREZ, A. \& SILOS RIBAS, M., op. cit., pp. 249-268; y VICIANO PASTOR, J., op. cit., pp. 171-182.

47. Ley 13/2013, de 2 de agosto, de fomento de la integración de cooperativas y de otras entidades asociativas de carácter agroalimentario (BOE núm. 185, de 3 de agosto). Norma valorada en positivo por la CNC en el Informe relativo al Anteproyecto de Ley de medidas para mejorar el funcionamiento de la cadena alimentaria (IPN 84/12. Reunión de 19 de diciembre de 2012). Vid. PEINADO GRACIA, J.I. (dir.) \& VÁZQUEZ RUANO, T. (coord.): Tratado de Derecho de sociedades cooperativas, 2 vols., Tirant lo Blanch, Valencia, 2019. 
cadena alimentaria. En este caso, se enuncia un modelo cooperativo empresarial, profesionalizado y con dimensión relevante al apostar por el fomento de la capacidad comercializadora y económica de este sector, a través de la iniciativa de integración de las cooperativas y otras formas jurídicas del asociacionismo agrario ${ }^{48}$. La intención prioritaria de esta propuesta regulatoria no es otra que generar valor, mejorar la rentabilidad, la competitividad y que el sector resulte más profesionalizado. De estos retos surgen dos iniciativas de relevancia práctica: de un lado, la aprobación por parte del Ministerio de Agricultura, Pesca y Alimentación del Plan Nacional de Integración Cooperativa para coordinar las políticas de fomento asociativo e impedir las medidas que puedan dispersar la oferta. Al momento de elaborar el presente trabajo, está vigente el Plan Estatal de Integración Asociativa $2015-2020^{49}$ en el que se ha reforzado el presupuesto del Programa Nacional de Desarrollo Rural para cumplir los objetivos planteados y se ha previsto un programa de formación de los Consejos Rectores de las Cooperativas Agroalimentarias.

De otro, se ha creado la figura de la Entidad Asociativa agroalimentaria Prioritaria $^{50}$. Se trata del reconocimiento a una entidad asociativa de su condición de agente dinamizador del sector agroalimentario, a efectos de fomentar la competitividad en dicho ámbito mediante el incremento de su dimensión. Las entidades asociativas van a ser: las cooperativas agroalimentarias, las cooperativas de segundo grado agroalimentarias, los grupos cooperativos agroalimentarios, las sociedades agrarias de transformación de carácter agroalimentario, las organizaciones de productores con personalidad jurídica, las reconocidas por la PAC y, en algunos casos, entidades civiles o mercantiles agroalimentarias.

\section{B. Especial referencia a la precursora Ley 12/2013 de medidas para mejorar el funcionamiento de la cadena alimentaria}

La aprobación de la Ley 12/2013 para mejorar los comportamientos comerciales de los distintos operadores que participan en la cadena de distribución alimentaria, como se ha indicado, fue pionera e innovadora en la materia. Básicamente en lo

48. Véase la Exposición de motivos de la Ley 13/2013.

49. Puede consultarse en el enlace electrónico: https://www.mapa.gob.es/es/alimentacion/temas/ integracionasociativa/planestatal2015-2020_tcm30-209732.pdf

50. El Real Decreto 550/2014, de 27 de junio, por el que se desarrollan los requisitos y el procedimiento para el reconocimiento de las Entidades Asociativas Prioritarias y para su inscripción y baja en el Registro Nacional de Entidades Asociativas Prioritarias, previsto en la Ley 13/2013, de 2 de agosto, de fomento de la integración de cooperativas y de otras entidades asociativas de carácter agroalimentario (BOE núm. 173, de 17 de julio). 
que concierne a la protección del sector primario como parte débil de la cadena y en cuanto al fomento de su adecuado funcionamiento. En este sentido, su objetivo fundamental fue la mejora de la actividad y organización de la cadena alimentaria y la minimización del desequilibrio en las relaciones comerciales entre los diferentes operadores con independencia de su volumen, a saber: desde la producción a la distribución de alimentos o productos alimenticios, incluyendo las relaciones entre operadores en el envasado, transformación o suministro para después poder comercializarlos $^{51}$.

En relación con lo señalado, la norma establece ciertos deberes contractuales que han de observar los operadores que intervienen en la cadena alimentaria, al igual que las limitaciones al ejercicio de determinadas prácticas comerciales consideradas contrarias a la leal competencia en el mercado. Las disposiciones contenidas en el texto de referencia, desde la perspectiva objetiva, se concretan en los contratos alimentarios y en el régimen de las prácticas comerciales abusivas. En cuanto a los primeros, se pretende garantizar su seguridad y eficacia imponiendo la exigencia formal de la constancia escrita respecto de los contratos alimentarios suscritos entre los operadores de la cadena de valor y con anterioridad al inicio de las prestaciones, a excepción de que el pago del precio se realice al contado contra la entrega de los productos alimenticios $^{52}$; y el contenido mínimo del contrato. Dicho contenido necesario se concreta no sólo en la identificación de las partes, de su objeto, del precio y la expresa indicación de todos los pagos (incluidos los descuentos) sino, además, en las condiciones del pago, las de entrega y puesta a disposición de los productos, los derechos y obligaciones de las partes, la información que las partes necesariamente deben suministrarse, la duración del contrato (incluyendo las condiciones de renovación y de modificación) y las causas, formalización y efectos de la extinción de la relación contractual.

En lo que concierne a las prácticas comerciales abusivas, se establece la prohibición expresa de las que a continuación se relacionan en cuanto las lleve a cabo un operador dominante sobre el resto de los que participan en la cadena alimentaria. De un lado, las modificaciones unilaterales del contrato y los pagos comerciales no previstos. En cuanto a aquéllas, sólo se admiten si se realizan por mutuo acuerdo

51. Asimismo, se extiende a las adquisiciones de animales vivos, piensos y materias primas para alimentación animal. Excluyéndose las relaciones comerciales de los agentes de la cadena alimentaria con operadores económicos ajenos al ámbito alimentario, al igual que con los consumidores y el canal de hostelería; y las que tienen por objeto la entrega del producto de un socio a su entidad asociativa, siempre que los socios estén obligados a ello por el contenido de los estatutos de la asociación a la que pertenecen.

52. En este planteamiento, las partes deben identificarse como operadores y documentar dichas relaciones comerciales mediante la expedición de la correspondiente factura. 
de las partes y se exige que los contratos alimentarios contengan las cláusulas en las que se prevea el procedimiento para su posible modificación y, en su caso, para la determinación de su eficacia retroactiva. Sobre los pagos comerciales adicionales que excedan del precio pactado, se establece su limitación a menos que se refieran al riesgo razonable de referenciación de un nuevo producto o a la financiación parcial de una promoción comercial reflejada en el precio unitario de venta al público y hayan sido pactados e incluidos en el contenido contractual.

Por otro lado, la limitación referida al suministro de información comercial sensible en el sentido de que no podrá exigirse a otro operador información sobre sus productos que no esté justificada en el contexto de la relación comercial y del efectivo cumplimiento de las obligaciones contractuales, a excepción de que así conste en las disposiciones del contrato concluido. La información comercial sensible que se obtenga en el proceso de negociación o ejecución de un contrato alimentario se destinará exclusivamente a los fines para los que se hubiera facilitado y, en todo caso, deberá observarse la confidencialidad de la misma.

Finalmente, se prevé la obligación que pesa sobre los operadores económicos de gestionar las marcas de productos alimentarios que ofrezcan al consumidor, tanto las propias como las de otros operadores. Queda limitado el aprovechamiento indebido por parte de un operador, y en beneficio propio, de la iniciativa empresarial ajena y los actos de publicidad ilícita por ser desleal mediante la utilización de elementos distintivos que provoquen riesgo de asociación o confusión con los de otro operador, o con marcas o nombres comerciales de otro operador ${ }^{53}$.

La realización en el mercado alimentario de las prácticas prohibidas por resultar abusivas para el sector comporta la comisión de una infracción administrativa en materia alimentaria. En este sentido, se reconoce tanto un específico control administrativo, como la tipificación de las infracciones y sanciones correspondientes, confiriendo el ejercicio de la potestad sancionadora a la Administración General del Estado (en concreto, al Ministerio de Agricultura y Pesca, Alimentación y Medio Ambiente -MAGRAMA-) y, si procede, a las Comunidades Autónomas. De este modo, es la Administración General del Estado la facultada para ejercer la mencionada potestad sancionadora cuando las partes contratantes tengan sus respectivas sedes sociales principales en diferentes Comunidades Autónomas, o en el caso de que el contrato afecte a un ámbito superior al de una Comunidad Autónoma en razón de la trazabilidad del alimento. Por su parte, la potestad sancionadora corresponderá a las Comunidades Autónomas en el resto de los supuestos.

53. Arts. 11 y 12 de la LCD, en relación con la LM, cuyo objeto es la regulación de los signos distintivos, en particular de la marca del producto o servicio como identificativo del mismo en el entorno comercial. 
En consecuencia, va a ser fundamental el papel de los inspectores de la Agencia de Información y Control Alimentario (AICA) facultados para desempeñar funciones relativas a la supervisión del cumplimiento de la Ley y de información y control de los mercados oleícolas, del sector lácteo y de los que reglamentariamente se determinen. Y, también, los mecanismos de coordinación entre las Administraciones Públicas para garantizar la Unidad de Mercado. La intención de tutela, en este caso, se focaliza en las relaciones comerciales que se produzcan entre los operadores que intervienen en la cadena alimentaria desde la producción a la distribución de alimentos o productos alimenticios, incluyendo las relaciones entre operadores en el envasado, transformación o suministro a fin de poder comercializarlos a posteriori ${ }^{54}$.

La regulación que nos ocupa promueve, asimismo, las buenas prácticas en la contratación alimentaria. Ello se traduce, de un lado, en el impulso y fomento por parte del Ministerio y de las organizaciones y asociaciones representativas de la producción, industria y distribución para crear un Código de Buenas Prácticas Mercantiles en la Contratación Alimentaria ${ }^{55}$ que incluya una lista de conductas comerciales prohibidas entre proveedores y compradores y, además, un conjunto de reglas mínimas y una coordinación entre las autoridades de control u órganos públicos independientes con capacidad de sancionar, iniciar una investigación de oficio y recibir las denuncias particulares que se hubieran presentado. Y, de otro, en la creación del Observatorio de la Cadena Alimentaria que asume las funciones del Observatorio de Precios de los Alimentos y otras facultades concretas ${ }^{56}$, como lo son: la realización del seguimiento del Código de Buenas Prácticas, fomentar las buenas conductas recogidas en el mismo y prever sistemas que resulten ágiles y seguros a fin de resolver los conflictos que se planteen. Al tiempo que le corresponde analizar y estudiar la estructura básica de los costes y de precios percibidos y pagados, junto a sus causas.

54. Asimismo, se extiende a las adquisiciones de animales vivos, piensos y materias primas para alimentación animal.

55. Resolución de 10 de diciembre de 2015, de la Dirección General de la Industria Alimentaria, por la que se publica el Código de Buenas Prácticas Mercantiles en la Contratación Alimentaria (BOE núm. 302, de 18 de diciembre). Para ampliar la información sobre el Código de Buenas Prácticas Mercantiles en la Contratación Alimentaria, puede accederse al siguiente contenido: https://www.mapa.gob.es/es/alimentacion/ temas/ley-de-medidas-para-mejorar-el-funcionamiento-de-la-cadena-alimentaria/codigobuenaspracticas\%5Ben_tcm 30-379788.pdf.

56. Puede consultarse en el siguiente enlace:

https://www.mapa.gob.es/es/alimentacion/temas/observatorio-cadena/ 


\section{La adecuación de la regulación nacional a las previsiones comunitarias sobre la cadena alimentaria. Intervención de la CNMC al respecto}

\section{A. Comentarios previos}

El marco europeo recogido en la Directiva (UE) 2019/633 sobre prácticas comerciales desleales en las relaciones entre empresas en la cadena de suministro agrícola y alimentario, como se ha indicado, será de obligado cumplimiento para los países miembros de la UE en el presente ańo. Aun cuando la base de esta norma trae causa en la novedosa Ley 12/2013 de medidas para mejorar el funcionamiento de la cadena alimentaria, el contenido de ésta precisa de ciertas modificaciones para ajustarse a las previsiones del tenor comunitario. A mayor abundamiento, debe recordarse que la Directiva (UE) 2019/633 es una norma de mínimos, lo que deja un amplio margen de actuación a los Estados miembros en el momento de su transposición. En base a dicha discrecionalidad, nuestro legislador ha actuado de forma diversa en cuanto a su transposición, pues no sólo se ha adoptado un texto normativo en la materia en el que se recogen con carácter de urgencia un elenco de medidas sobre agricultura y alimentación que suponen modificaciones en diversas previsiones ${ }^{57}$, sino también se ha optado por el mantenimiento de la norma precursora y de referencia. No obstante, en este último supuesto, se ha presentado una nueva ley para modificar las disposiciones contenidas en la misma.

De un lado, a nivel interno se ha aprobado la Ley 8/2020 por la que se adoptan medidas urgentes en materia de agricultura y alimentación ${ }^{58}$. Dicha norma recoge un conjunto de reglas precisas para minimizar los factores perjudiciales y mejorar la capacidad negociadora, la equidad de las relaciones comerciales y el reparto justo de los costes de carácter general del sector primario. De su lectura se infieren los diversos retos a los que se está enfrentando el sector agroalimentario: la caída sostenida de precios percibidos por los agricultores, el aumento de los daños por fenómenos

57. En concreto, en el art. 1 de la Ley $8 / 2020$ se modifica la Ley 12/2013 de medidas para mejorar el funcionamiento de la cadena alimentaria; en el 2 la Ley 35/2006, de 28 de noviembre, del Impuesto sobre la Renta de las Personas Físicas y de modificación parcial de las leyes de los Impuestos sobre Sociedades, sobre la Renta de no Residentes y sobre el Patrimonio (BOE núm. 285, de 29 de noviembre); y en el 5 la Ley 23/2015, de 21 de julio, Ordenadora del Sistema de Inspección de Trabajo y Seguridad Social (BOE núm. 174, de 22 de julio).

58. Ley $8 / 2020$, de 16 de diciembre, por la que se adoptan determinadas medidas urgentes en materia de agricultura y alimentación (BOE núm. 328, de 17 de diciembre) y que deriva del RD-Ley 5/2020, de 25 de febrero, por el que se adoptan determinadas medidas urgentes en materia de agricultura y alimentación (BOE núm. 49, de 26 de febrero) al que deroga. 
climáticos extremos, tensiones comerciales, volatilidad de las cotizaciones de las materias primas, el incremento de los costes de los insumos agrarios y ganaderos, el impulso de exigencias en la producción y la falta de equilibrio en la fijación de precios en la cadena alimentaria. Así como, la vulnerabilidad del sector agrario singularizado por su atomización, invariabilidad y con una notable rigurosidad de la demanda. En razón de ello, la norma prevé puntuales medidas regulatorias tendentes a acrecentar la cadena alimentaria, tal es el caso de la imposición a los operadores de abonar un precio igual o mayor al coste de producción del producto de que se trate al que sea inmediatamente anterior en que haya incurrido o asumido dicho operador ${ }^{59}$ y la incorporación del coste de producción en el precio como elemento mínimo y básico de los contratos ${ }^{60}$. Impidiendo, en todo caso, que en la concreción del coste se introduzcan factores que lo puedan distorsionar.

De otro, como hemos adelantado, se hace una transposición de mínimos y se conservan los elementos esenciales y la sistemática de la Ley $12 / 2013$, pero con las precisas adaptaciones y posibles mejoras en virtud de la actual regulación comunitaria $^{61}$. Consecuencia de lo cual, junto a la intención de elaborar el Proyecto de ley para el desperdicio alimentario, se presentó el Proyecto de reforma de la Ley de la Cadena Alimentaria $^{62}$ al objeto de fomentar la innovación en dicha cadena, conferir mayor transparencia a su funcionamiento e incrementar el reparto más justo del valor. Ello, a su vez, conlleva que se atribuya un incremento de la tutela del eslabón de la cadena alimentaria calificado como débil. Esta ambiciosa finalidad trata de llevarse a cabo con unas modificaciones de mayor calado y que se centran, prioritariamente, en la ampliación de su ámbito de aplicación ${ }^{63}$ y en la limitación de nuevas prácticas comerciales desleales que repercuten negativamente en los precios para el agricultor. En concreto, se hace referencia a la mencionada Ley $16 / 2021$, por la que se modifica la Ley 12/2013. Teniendo en cuenta que la superación del desequilibrio en la

59. Art. 1.3 de la Ley 8/2020, por el que se incluye un nuevo artículo 12 ter a la Ley 12/2013.

60. Art. 1 . 1 de la Ley 8/2020, por el que se modifica letra c) del apartado 1 del art. 9 de la Ley 12/2013 y se añade una nueva letra j). En cuyo caso, se debiera haber incluido alguna referencia a los contratos-tipo.

61. Además, en relación con la valoración realizada en la tramitación del Plan Estratégico de la PAC. En concreto, véanse los arts. 2 y 14 bis y el nuevo Título VII de la Ley 8/2020.

62. Proyecto de Ley por el que se modifica la Ley 12/2013, de 2 de agosto, de medidas para mejorar el funcionamiento de la cadena alimentaria (BOCG. Congreso de los Diputados, Serie A, núm. 36, de 13 de noviembre 2020). Aprobación de la Ley 16/2021, de 14 de diciembre, por la que se modifica la Ley 12/2013, de 2 de agosto, de medidas para mejorar el funcionamiento de la cadena alimentaria (BOE núm. 299, de 15 de diciembre).

63. En cuanto al ámbito material, el nuevo texto se extiende a los alimentos y productos alimenticios, las materias primas y otros productos recogidos en el Anexo I del TFUE. 
cadena agroalimentaria parte de la prohibición de los comportamientos comerciales desleales entre los operadores que lo generan y que comprometen la capacidad de negociación de las partes contratantes.

En consecuencia, se pretende que la norma interna resulte aplicable tanto a nivel del mercado nacional, como comunitario cuando participe un operador establecido en España con otro operador europeo e, incluso, de un país tercero. Cuando interviene un operador español y otro comunitario la norma nacional habrá de observarse siempre que no sea de aplicación la legislación del otro Estado miembro. Asimismo, se atenderán las prohibiciones y sanciones contenidas en el texto nacional en las relaciones que se desarrollen entre un operador establecido en España y otro de un tercer país.

De forma somera, por cuanto será objeto de análisis a continuación, cabe poner de manifiesto que en materia contractual la principal novedad es la exigencia en la práctica totalidad de las operaciones de la constancia escrita de los contratos. Salvando de dicho requerimiento a las cooperativas agroalimentarias que están facultadas para sustituir este contrato por una prescripción concreta de los plazos de pago, aprobada por su órgano gestor (Consejo Rector) y a la que se le dé la suficiente publicidad.

Respecto de las prácticas desleales, se incluyen en el conjunto de las mismas los comportamientos recogidos en la norma europea, como la modificación unilateral de los contratos en lo que se refiere al volumen o la devolución de los productos que no se hubieran vendido. En materia de infracciones, el nuevo tenor introduce diversos incumplimientos que no se habían recogido con anterioridad y, en otros casos, se recalifican las consecuencias de las posibles infracciones en cuanto a su gravedad (de sanción leve a grave $)^{64}$.

Sin embargo, aun cuando la pretensión de la reforma, en general, ha de valorarse en sentido positivo parece que su resultado mediato no se ha considerado del mismo modo como lo ha puesto de manifiesto la CNMC en relación con la repercusión para la competencia en el sector y de cuyo estudio procedemos a ocuparnos seguidamente.

\section{B. Orientaciones realizadas por la Comisión de Competencia}

El proceder de la Comisión de Competencia respecto de las disposiciones sobre el funcionamiento de la cadena alimentaria se ha hecho depender del requerimiento

64. Como sucede con la cancelación de un pedido 30 días antes de la fecha de entrega o la exigencia de pagos adicionales sobre el precio pactado. Sobre ello han opinado, entre otros, CRESPO PEREIRA, D. \& ARIAS VARONA, F.J., op. cit., pp. 9-10; por cuanto la iniciativa de la propuesta surge del Ministerio de Agricultura, Alimentación y Medio Ambiente. 
que a tal fin plantea el propio Consejo de Defensa de la Competencia o, en su caso, a instancia de otras administraciones públicas facultadas para ello.

En razón de la potestad que ostenta para promover la competencia, la CNC emitió en 2011 un Informe sobre las relaciones entre los fabricantes y distribuidores en el sector alimentario ${ }^{65}$ en el que se examina el impacto de los cambios en la distribución minorista en la competencia del mercado alimentario, particularmente, en cuanto a la marca del distribuidor y al creciente poder de negociación de la distribución minorista sobre el resto de los eslabones de la cadena. En dicho Informe se estudian, de un lado, las relaciones comerciales llevadas a cabo entre fabricantes y distribuidores de productos alimentarios en términos de su poder de negociación relativo y, de otro, las consecuencias de las mismas para el funcionamiento del sector. De modo específico, se analizan ciertas prácticas comerciales consideradas abusivas por la CNC en cuanto que las aplican los grandes distribuidores y, junto a ello, los efectos adversos que su ejecución ocasiona en la competencia en el mercado.

En primer término, se pretende conseguir la entrada de nuevos operadores para que incremente la competitividad sobre los distribuidores mediante la eliminación de las restricciones al establecimiento y al ejercicio de la actividad comercial ${ }^{66}$. En segundo lugar, se valoran los efectos perjudiciales en el adecuado funcionamiento del mercado y en la competencia en base a ciertas prácticas comerciales en la distribución y se proponen medidas tendentes a evitarlas. En cuanto a las que son de carácter contractual, se refieren a la precisa formalización de las relaciones comerciales por escrito y la previsión de limitaciones sobre las modificaciones retroactivas de las condiciones contractuales. En lo que hace a las actuaciones en el mercado, en materia de pagos comerciales de fabricantes a distribuidores se impone que sean previsibles, transparentes y proporcionales, junto a la atención a las exigencias de información comercial sensible por parte de los distribuidores a sus proveedores, las consecuencias negativas de las "cláusulas de cliente más favorecido" por las que se garantiza el mejor precio que haya ofrecido la otra parte a un tercero y los intercambios de información entre proveedores y distribuidores sobre sus relaciones comerciales con terceros.

Por último, el Informe se ocupa del ámbito regulatorio, respecto del cual se pone de relieve el incremento normativo y de códigos de conducta a nivel autonómico en

65. Informe sobre las relaciones entre fabricantes y distribuidores en el sector alimentario de la Comisión Nacional de la Competencia (CNC, en aquel momento), noviembre de 2011. Disponible en el recurso electrónico: https://www.cnmc.es/sites/default/files/1186011_1.pdf

66. En base a la Directiva 2006/123/CE del Parlamento Europeo y del Consejo, de 12 de diciembre de 2006, relativa a los servicios en el mercado interior (DOUE L376, de 27 de diciembre). 
relación con las prácticas comerciales, lo que la $\mathrm{CNC}$ aprecia que es un riesgo que afecta al propio mercado alimentario interior y al régimen de competencia en el mismo ${ }^{67}$.

Con carácter general, el Consejo de la Comisión aprobó el Informe sobre competencia y sector agroalimentario en el que analiza la aplicación de las normas de competencia a este sector ${ }^{68}$. En concreto, la CNC concluye la necesidad de que -en el ejercicio de su actividad económica- los productores agrarios y sus asociaciones y las organizaciones interprofesionales, si procede, observen las normas de competencia. Esto es, fundamentalmente, las previsiones de los artículos 101 a 109 del TFUE y la normativa nacional antes mencionada (LDC y el Real Decreto 261/2008, de 22 de febrero ${ }^{69}$ ) ya que se trata de la base jurídica del futuro funcionamiento de la cadena agroalimentaria. Y, además, la regulación propia del sector. Por tanto, corresponde a dichos sujetos "autoevaluar" si las prácticas comerciales que ejercen en el mercado están encuadradas en las conductas restrictivas de la competencia que precisa la norma de aplicación.

La Comisión se muestra concreta en relación con la prohibición de la venta por debajo del coste de producción en el sector agroalimentario y recuerda la prohibición de los posibles acuerdos sobre precios en cualquiera de sus formas (determinación directa, recomendaciones u otro modo) que evite que se definan libremente ${ }^{70}$. En igual sentido, la fijación de precios que tiene por objeto la previsión de un nivel mínimo por debajo del cual no se pueda ofertar o demandar en relación con los precios en origen en el mercado agroalimentario. El inconveniente que surge, a este respecto, se halla en los efectos adversos para la eficiencia en la cadena de valor y para el consumidor final, y la falta de efectividad en lo que hace a la garantía de una renta determinada a los agricultores. Más aún en un mercado de productos con una oferta caracterizada por ser atomizada y con una notable serie de canales de distribución y venta al público.

Centrándonos de forma específica en cuanto al funcionamiento de la cadena alimentaria y en los textos normativos al respecto, la CNC inicialmente publicó el Informe sobre el Anteproyecto de Ley de Medidas para Mejorar el Funcionamiento de la

67. Véanse las pp. 124 a 133 del Informe.

68. Informe sobre competencia y sector agroalimentario de la CNC de 26 de septiembre de 2017. Disponible en el recurso electrónico: https://www.cnmc.es/sites/default/files/1185937_6.pdf

69. Al igual, el Real Decreto 657/2013, de 30 de agosto, y la Ley 1/2002, de 21 de febrero, ya referidos. En el ámbito comunitario, el Reglamento (CE) 1/2003 del Consejo, de 16 de diciembre 2002, y el Reglamento (CE) 139/2004 del Consejo, de 20 de enero.

70. Art. 101 del TFUE y art. 1 de la LDC, a excepción de acuerdos indispensables para conseguir las eficiencias asociadas a un acuerdo de ámbito mayor. 
Cadena Alimentaria ${ }^{71}$ de acuerdo con las competencias consultivas que le corresponden en materia regulatoria cuando se afecta a la competencia en el mercado ${ }^{72}$. En este sentido, se parte del objetivo prioritario de la iniciativa que se centra en alcanzar un mejor funcionamiento de la cadena alimentaria, a través de la regulación de actuaciones comerciales entre los distintos operadores que intervienen en la misma. Incluyendo unos deberes de carácter contractual (constancia escrita y necesidad de firma ${ }^{73}$ ) y un conjunto de prácticas abusivas ${ }^{74}$. Además del régimen de infracciones y sanciones administrativas para reprimir, en su caso, su incumplimiento. Si bien, la Comisión considera que estos retos deben estar en conexión con la eficiencia a corto, a medio y a largo plazo y con la productividad y competitividad de los sectores implicados. La falta de esta conciliación traerá como consecuencia que la regulación no consiga mejorar el funcionamiento de la cadena alimentaria y ello por cuanto la CNC aprecia que el desequilibrio existente entre las partes contratantes es una característica del mercado y no tanto un fallo del mismo. Así, la actuación normativa a este respecto ha de ser cautelosa y fundarse en los criterios de proporcionalidad y necesidad. Respecto de este último, el Informe muestra su reprobación al estimar que el conjunto de prácticas abusivas contempladas en el Anteproyecto se encuentra recogido en la LCD, bien en tipos específicos o bien en la cláusula general de deslealtad ${ }^{75}$. Haciendo extensiva esta consideración, de igual forma, al régimen de protección administrativo previsto en esta iniciativa (régimen sancionador).

Tras este primer Informe, el Ministro de Agricultura, Alimentación y Medio Ambiente solicita a la CNC su parecer respecto del contenido del Proyecto de Ley de mejora de la cadena alimentaria aprobado ${ }^{76}$. En esta ocasión el Informe de la Comisión sobre las implicaciones de ciertas cuestiones del mismo en lo que hace a la competencia

71. Informe relativo al Anteproyecto de Ley de medidas para mejorar el funcionamiento de la cadena alimentaria de la CNC (IPN 84/12. Reunión de 19 de diciembre de 2012).

72. Art. 25. a) de la LDC.

73. Exceptuándose el caso de las cooperativas (art. 3 del Proyecto que modifica el art. 8.1 ${ }^{\circ}$ de la Ley 12/2013). Adviértase que esta previsión no queda recogida en el texto de la Directiva (UE) 2019/633, a la que transpone.

74. Véase el art. 5 del Proyecto sobre la prohibición de las modificaciones de las condiciones contractuales en el suministro (como la frecuencia, método, lugar, calendario o volumen o la entrega, las normas de calidad, condiciones de pago o los precios) a menos que exista un acuerdo previo, y el art. 6 que incorpora el art. 14 bis al texto de la norma, incluyendo prácticas comerciales desleales negras (prohibidas, en todo caso) y grises (prohibidas, salvo previsión en el contrato).

75. Sobre ello, vid. ARAUJO BOYD, M. \& FERRER VIEYRA, E., op. cit., pp. 16-21. En un sentido contrario, vid. CRESPO PEREIRA, D. \& ARIAS VARONA, F.J., op. cit., pp. 10-15.

76. Proyecto de Ley de 8 de febrero de 2013 (BOCG. Congreso de los Diputados, Serie A, núm. 37, de 15 de febrero). 
efectiva en los mercados se considera adicional al anterior ${ }^{77}$. Los aspectos analizados en este supuesto se concretan en los que se relacionan a continuación. De un lado, la incorporación de la delimitación conceptual de "coste de producción primaria" o, lo que es lo mismo, del valor estadístico de referencia calculado de forma periódica por la autoridad competente en razón de los costes necesarios de producción del producto sin transformar por parte de un productor primario. De otro, su indicación en el contenido del contrato y en relación con la referencia expresa del precio, en cuanto que se indique que éste no sea inferior al coste de producción primaria vigente a la fecha de formalización del contrato en los casos en los que dicho coste se haya establecido. Por último, el reconocimiento al Observatorio de la Cadena Alimentaria (OCA) de la facultad de fijar dichos costes de producción primaria si se detectan indicios de abuso de posición dominante. La CNC concluye en su Informe adicional que la fijación de precios mínimos referida (directa o indirectamente) en el sector agrario no puede admitirse porque perjudica la eficiencia en los mercados y la garantía de la competencia efectiva, lo cual limitaría el funcionamiento de la cadena alimentaria $^{78}$. Y, como es obvio, tampoco resulta compatible con el reconocimiento constitucional de la libertad de empresa.

Aprobada la Ley 12/2013 de medidas para mejorar el funcionamiento de la cadena alimentaria, tras la superación del correspondiente proceso parlamentario, se plantea de nuevo la consulta a la Comisión de Competencia sobre el Anteproyecto de Ley por la que se modifica la Ley 12/201379. Si bien, teniendo en cuenta que la CNMC no se pronunció respecto del RD-Ley 5/2020 del que trae causa la Ley 8/2020 que lo deroga -a pesar de haber sido el primer intento para transponer al ámbito interno la norma comunitaria-, en este nuevo documento la Comisión incluye algunas anotaciones sobre el mismo.

Pese a que el RD-Ley 5/2020 introdujo medidas como la prohibición de prácticas de venta por debajo del precio de coste o la de retribuir a los productores por debajo de los costes de producción, entre otras, el Informe de la CNMC puntualiza este contenido en varios sentidos. Respecto de la identificada como "limitación de la destrucción de valor en la cadena”, entiende que se trata de la prohibición de venta a

77. Informe Artículo 25. Tramitación Proyecto de Ley de la Cadena Alimentaria de la CNC (Reunión de 24 de abril de 2013).

78. Sin embargo, el legislador no incorpora esta cuestión al texto definitivo (puede consultarse: SÁNCHEZ HERNÁNDEZ, Á.: "Los contratos alimentarios en la Ley de la calidad alimentaria: referencia a la normativa y doctrina italiana 'dei contratti di cessione dei prodotti agrícola e agroalimentaria”, Actualidad Civil, no 3 , 2015, p. 3).

79. Informe IPN/CNMC/015/20, de 2 de septiembre de 2020. 
pérdida en la cadena alimentaria y en cuanto al conjunto de operadores que intervienen en ésta. Y ello, aun cuando la norma que regula el comercio minorista la permite a consumidores finales, siempre que no se repute desleal ${ }^{80}$. En otro orden, se pone de manifiesto el riesgo que implica no haber definido debidamente el deber de que los precios de los contratos alimentarios cubran los costes de producción, ni la determinación de la parte contractual que está obligada a verificar el cumplimiento del coste efectivo de producción en la transacción. Pues, dicha carencia, puede suponer que los contratos resulten más complejos y que se favorezca el alineamiento de precios, así como que se limite la seguridad jurídica de los acuerdos comerciales.

En relación con el contenido propio del Anteproyecto de Ley, la CNMC ha cuestionado algunos aspectos, aunque nos detendremos en los que en la práctica de la cadena alimentaria resultan más controvertidos. En primer término, la perspectiva del ámbito de aplicación material y territorial de la misma a cualquier operación comercial ${ }^{81}$. El debate, en este sentido, se centra en el vacío del reconocimiento de que la operación que trata de valorarse genere un desequilibrio por las distintas posiciones de negociación de las partes contratantes en la operación comercial o la relación de dependencia entre ellos. La alusión genérica a toda operación comercial afecta, por su imprecisión, a la libertad comercial de los operadores. A mayor abundamiento, se pueden llevar a cabo prácticas comerciales en el mercado que no siempre afectan a la competencia en el mismo, pero que se consideran desleales por sus efectos en razón del desequilibrio en el poder negociador entre las partes o en la posición de dependencia. Desde esta óptica, la normativa proyectada podría resultar ineficiente, por cuanto aquellos problemas de la cadena agroalimentaria habrán de ser atajados en origen, es decir identificando los elementos que implican desequilibrios en el poder de negociación comercial entre las partes favoreciendo un mayor tamańo de los productores y eliminando las barreras a la apertura y funcionamiento de establecimientos de distribución alimentaria minorista. Téngase en cuenta que se mantiene la exclusión de las entregas de productos a las cooperativas por parte de los socios.

80. Véase el art. 14 de la Ley de ordenación del comercio minorista. Las ventas con pérdida serán desleales en los siguientes casos: a) Cuando sea susceptible de inducir a error a los consumidores acerca del nivel de precios de otros productos del mismo establecimiento. b) Cuando tenga por efecto desacreditar la imagen de un producto o de un establecimiento ajeno. c) Cuando forme parte de una estrategia encaminada a eliminar a un competidor o grupo de competidores del mercado. d) Cuando forme parte de una práctica comercial que contenga información falsa sobre el precio o su modo de fijación, o sobre la existencia de una ventaja especifica con respecto al mismo, que induzca o pueda inducir a error al consumidor medio y le haya hecho tomar la decisión de realizar una compra que, de otro modo, no hubiera realizado.

81. Art. 1 del Proyecto que modifica el art. 2 de la Ley 12/2013, en el que se reconoce la aplicabilidad de sus disposiciones a las transacciones comerciales de importe superior a 2.500 euros internas y las que se lleven a cabo a nivel comunitario. 
En segundo lugar, el régimen de las prácticas comerciales desleales verificables en la cadena agroalimentaria. La transposición de mínimos que hace nuestro legislador implica que se mantengan los comportamientos desleales incluidos en la norma de referencia y que, al mismo tiempo, se incorporen las novedades previstas en la Directiva comunitaria ${ }^{82}$. Sin embargo, el conjunto de conductas prohibidas en todo caso que se engloban en la lista de "prácticas negras" y las "prácticas grises" que quedan limitadas, a menos que se hubieran previsto en el contenido contractual, no es aceptado en positivo en su totalidad. La justificación que, en este sentido, puede hacerse parte del posible desequilibrio que en las relaciones comerciales se genere entre los operadores y que hace que la cadena de suministro alimentario resulte vulnerable a las prácticas desleales, lo cual confirma la antes denotada imprecisión de su contenido. Pero es que, al mismo tiempo, el texto normativo elude la referencia al orden de aplicación normativa en relación con las prácticas desleales en el mercado, teniendo en cuenta la diversidad jurídica existente en este ámbito. En la medida en que, respecto de ciertas prácticas desleales, confluyen diversas previsiones normativas como las de competencia desleal, la regulación de las marcas, la defensa de la competencia, las disposiciones de la ordenación del comercio minorista o la norma sobre la tutela de los secretos empresariales. En concreto, el contenido de la LCD va a resultar de aplicación a los empresarios, profesionales y personas físicas o jurídicas que participen en el mercado, y en cuanto a las prácticas desleales contrarias a las exigencias de la buena fe y a otros supuestos incluidos de manera expresa en su tenor. Reconociéndose, por su parte, en la regulación de la cadena alimentaria prácticas desleales singulares en razón del propio sector, así las que son contrarias a los principios de buena fe y comercio justo. La mencionada divergencia puede acarrear un supuesto de inseguridad jurídica y una posible diversidad de actuaciones administrativas al respecto.

Finalmente, la CNMC ha evaluado el régimen sancionador y las infracciones derivadas de la falta de observancia de las normas del Anteproyecto. En éstas últimas, no sólo se incorporan nuevas infracciones leves (como la cancelación de un pedido 30 días antes de la fecha de entrega) y graves (obstrucción de la inspección), sino también la recalificación de otras conductas comerciales (la imposición de pagos adicionales o asunción de costes sobre el precio pactado se califica ahora como infracción grave). En igual sentido, se incluyen mejoras de naturaleza procedimental tendentes a incrementar la eficiencia en la gestión y la seguridad jurídica. El régimen sancionador se ha simplificado y se establecen medidas que tratan de coordinar de forma efectiva el sector agroalimentario y otros regímenes y autoridades sancionadoras. En cuanto al que nos ocupa, se dota a la AICA de la consideración de autoridad 
de control nacional en la materia y su Dirección tendrá la competencia decisoria en sanciones pecuniarias de menor cuantía, lo que implica la distinción entre la función instructora y la resolutoria en los procedimientos sancionadores. Dicha Entidad va a ser, al mismo tiempo, punto de contacto y cooperación con otras autoridades facultadas para controlar el cumplimiento de la regulación y con la Comisión Europea. A pesar de que el contenido valorado dispone formas de coordinación entre las administraciones, la CNMC determina la necesidad de reforzar la cooperación entre las que están dotadas de competencias en materia sancionadora y de supervisión ${ }^{83}$. Al igual que se requiere precisar el sistema indemnizatorio que le es de aplicación a los que infringen el contenido de la normativa y los parámetros de su determinación. En definitiva, se sugiere revisar el régimen sancionador administrativo, por cuanto se trata de relaciones contractuales mercantiles entre operadores económicos sometidas a la regulación de obligaciones y contratos y a las normas propias de la competencia desleal, la defensa de la competencia y la propiedad industrial ${ }^{84}$, las cuales ya disponen de su propio régimen sancionador.

\section{Repercusiones de la reforma normativa en las entidades de economía social}

La modificación de la Ley 12/2013 para adaptarla al contenido previsto en la Directiva (UE) 2019/633, relativa a las prácticas comerciales desleales, es precisa y necesaria. Fundamentalmente a fin de alcanzar los objetivos indicados por ésta, a saber: incrementar la transparencia en la cadena alimentaria, equilibrar las relaciones entre sus distintos eslabones y conseguir la colaboración entre los que forman parte de la misma. Si bien, el contenido del Proyecto de reforma de la Ley de la Cadena Alimentaria y, actualmente, el texto de la Ley 16/2021 tienen un especial alcance en lo que concierne a las entidades de economía social, en particular sobre las cooperativas agroalimentarias, en concreto en el ejercicio de la función que vienen a desempeñar en la cadena de valor de dichos productos. Más aun en cuanto a la superación de los comportamientos desleales desde la limitación de los elementos que favorecen los desequilibrios en la facultad de negociación de las partes contratantes y del impulso de un mayor tamaño de los sujetos productores.

83. Informe relativo al Anteproyecto de Ley de medidas para mejorar el funcionamiento de la cadena alimentaria de la CNC (IPN 84/12. Reunión de 19 de diciembre de 2012).

84. El propio art. 7 de la Ley 12/2013 reconoce que el contenido de las relaciones que regula, y la aplicabilidad de los principios rectores en la ejecución e interpretación de las mismas, se somete a la normativa de defensa de la competencia, sin perjuicio de lo dispuesto en la normativa comunitaria. 
Las cooperativas agroalimentarias, como es sabido, se refieren a las entidades cooperativas que aglutinan a agricultores y/o ganaderos para poner en común sus recursos en concretas áreas de actividad. Junto a los servicios proporcionados, la labor principal de las mismas es la comercialización común de los productos generados por los socios que la integran. Conformando dichas entidades el primer eslabón de la mencionada cadena de distribución "de la granja a la mesa" como indica la norma comunitaria. De forma somera, en cuanto a la relevancia de estas cooperativas, conviene indicar que la forma cooperativa y el asociacionismo agrario son los aspectos fundamentales en los que se ha apoyado la transformación del sector agroalimentario en el ámbito nacional y que, en conjunto y según sus funciones, se pueden establecer en la mayor parte de la cadena de valor.

Siguiendo los datos señalados por el Observatorio Socioeconómico del Cooperativismo Agroalimentario Español (OSCAE) ${ }^{85}$, las Entidades Asociativas Agrarias (EAAs) se conforman por aproximadamente un total de 3.700 entidades cooperativas agrarias (de $1^{\circ}$ y $2^{\circ}$ grado) del ámbito agroalimentario nacional con una facturación de unos 34 mil millones de euros en el pasado año. Ello supone el 90\% de su composición, siendo el resto Sociedades Agrarias de Transformación (SAT), cooperativas de utilización de maquinaria agraria (CUMAS) y cooperativas de explotación comunitaria de la tierra (CEC), entre otras formas empresariales civiles y mercantiles. Dichas entidades están representadas por la organización Cooperativas Agro-alimentarias de España, la cual aglutina alrededor de 1.172.226 de socios cooperativistas en nuestro territorio y en los diversos subsectores, haciendo especial referencia a los siguientes: frutas y hortalizas, aceites de oliva, vinos, lácteos, ovino y caprino, cereales y alimentación animal. Aunque la relevancia de las cooperativas en el entorno agroalimentario no sólo destaca a nivel interno, sino que es reseńable su creciente presencia en los mercados internacionales ${ }^{86}$.

Los aspectos de la reforma normativa que afectan, en mayor medida, a las cooperativas agroalimentarias pueden concretarse en los temas que se exponen a continuación. En primer término, en cuanto al marco contractual, en el que la novedad es la exigencia en la práctica totalidad de las operaciones de la constancia escrita de

85. Hacemos referencial al Estudio "El cooperativismo agroalimentario. Macromagnitudes del Cooperativismo Agroalimentario Español” del Observatorio Socioeconómico del Cooperativismo Agroalimentario Español (OSCAE) elaborado en 2018 y publicado en junio de 2019 (para ampliar la información, véase: http://www.agro-alimentarias.coop/ficheros/doc/05987.pdf).

86. En concreto, el $34 \%$ de las cooperativas exportan y representan el 18\% de la facturación exportadora del conjunto del sector agroalimentario. Manifestándose una tendencia creciente en valor en lo que respecta a las exportaciones de las cooperativas agroalimentarias y de la facturación de las mismas en los mercados exteriores. Véase la obra AA.VV.: Tratado de Derecho...op.cit., vol. I. 
los contratos. De este modo, la regulación exige exclusivamente para someterse a la normativa sobre contratación que se trate de un precio superior al umbral que se ha estimado razonable (2.500 euros) conforme a la Ley 7/2012, de 29 de octubre ${ }^{87}$. Sin embargo, quedan al margen de dicha exigencia las cooperativas agroalimentarias, al entenderse que respecto de las mismas no es preciso conferir especiales garantías a la libre conformación de la voluntad contractual. Pues, éstas, están facultadas para sustituir este contrato por una prescripción concreta o acuerdo de los plazos de pago. Las imposiciones que se establecen en este sentido son fundamentalmente dos: de un lado, que dicha disposición sea aprobada por el órgano gestor cooperativo, el cual se corresponde con el Consejo Rector; y, de otro, que se le dé la suficiente publicidad entre las partes interesadas.

En segundo lugar, cabe hacer alusión a las relaciones de los socios cooperativos con las entidades de las que forman parte. En cuyo caso, expresamente se excluyen de la consideración de relaciones comerciales, quedando al margen de la aplicación de la norma ${ }^{88}$, las entregas de producto que los socios realicen a las cooperativas y otras entidades asociativas, siempre que éstas deriven de una obligación reconocida estatutariamente. No obstante, respecto de este planteamiento, la reforma prevé el deber de que la entrega se formalice por escrito en un contrato alimentario e individualiza$\mathrm{do}^{89}$. A menos que los estatutos u otros acuerdos de la cooperativa establezcan, con anterioridad a la entrega, el procedimiento de determinación del valor del producto suministrado por parte de los socios y el calendario de liquidación correspondiente y que los socios de la entidad tengan conocimiento de ello. Por consiguiente, dicha salvedad va a implicar la existencia de una comunicación fehaciente a los interesados, la cual habrá de incluirse en el acuerdo y tendrá que ser aprobada por el órgano gestor de la entidad.

El interrogante que la posibilidad antes indicada hace surgir en la práctica comercial de las sociedades cooperativas es el relativo a que con carácter previo se concrete el valor del producto vía estatutaria o por un acuerdo cooperativo. Es decir, sería suficiente para eludir dicho requerimiento con una modificación de los estatutos o con la aprobación de un acuerdo en el que se defina el valor de la producción que recibe el socio cooperativo y en el que se precisen los plazos de liquidación del mismo. Aspecto que, consideramos, no se ajusta a la finalidad de la reforma normativa que se analiza,

87. Ley 7/2012, de 29 de octubre, de modificación de la normativa tributaria y presupuestaria y de adecuación de la normativa financiera para la intensificación de las actuaciones en la prevención y lucha contra el fraude (BOE núm. 261, de 30 de octubre).

88. Art. 2 de la Ley 12/2013.

89. Véase el contenido del art. 8 del Anteproyecto de Ley. 
la cual se ha de ceñir a la ampliación del margen de negociación en la cadena de valor y, en consecuencia, en la moderación de los costes del sector productor. Razón que nos permite apreciar que ello confronta con el que es el propio funcionamiento de la sociedad cooperativa agroalimentaria y, al mismo tiempo, genera inseguridad jurídica. En las entidades cooperativas es práctica habitual y admitida por los sujetos el almacenamiento de la producción y su venta o comercialización común en razón de la mejor cotización en el mercado de esa producción generada por los socios, en beneficio de éstos y en base a la liquidación que perciben. Y ello hace que la función básica de la cooperativa genere valor ańadido a los productos, se reduzcan los costes y, a su vez, se suministren diversos servicios. La imposición señalada supondría la determinación de unos plazos que afectan de modo directo al funcionamiento cooperativo.

Siguiendo el contenido de la reforma planteada y en atención al sector de las cooperativas agroalimentarias y a las especialidades del mismo, tampoco resulta admisible el que no se haya definido debidamente y con precisión el deber de que los precios de los contratos alimentarios encuadren los costes de producción, ni la determinación de la parte que está obligada a verificar el cumplimiento del coste efectivo de producción en la transacción. Vacíos que pueden generar no sólo que las disposiciones contractuales resulten más complejas y, en su caso, provocar alineamientos de precios, cuanto el perjuicio a la seguridad jurídica de las relaciones comerciales. La referencia del precio a los costes efectivos de producción es una materia cuyo interrogante se mantiene desde el Real Decreto-Ley 5/2020 y que, a pesar de su observancia formal, sigue sin cumplirse de manera adecuada.

\section{Recopilaciones finales}

Los textos normativos vigentes en el ámbito empresarial y de mercado tienen por finalidad establecer mecanismos que tutelan los intereses de los que forman parte del entorno empresarial en un sentido amplio. Esto es, tanto si se trata de empresarios, competidores, consumidores y/o usuarios o el resto de participantes. No obstante, y en lo que hace al mercado de productos agroalimentarios, la preocupación de la Comisión Europea se ha centrado de modo específico en la garantía de los intereses de los que forman parte del mercado agroalimentario y con un importante reflejo en el ámbito empresarial de la cadena de suministro de alimentos, singularizado por la atomización de los agentes que participan en las fases productivas y la volatilidad de los costes de producción. Razón que ha traído como consecuencia la aprobación de la Directiva (UE) 2019/633, relativa a las prácticas comerciales desleales en las rela- 
ciones entre empresas en la cadena de suministro agrícola y alimentario. Este marco europeo de mínimos pretende limitar las prácticas comerciales desleales en la cadena de suministro de alimentos, siendo su finalidad propiciar la igualdad de oportunidades de las pequeñas y medianas empresas alimentarias y agrícolas, de los productores y de los agricultores, al entender que se trata de un sector vulnerable en la cadena de distribución de alimentos por el diverso poder de negociación con el que cuentan en las relaciones comerciales y que es reflejo de la dependencia económica.

La norma referida ha de valorarse en un sentido positivo al suponer una mejora en el desarrollo de la actividad del mercado agroalimentario por parte de las entidades de economía social, propiciando un entorno empresarial justo y leal, y una mejora del desenvolvimiento de la actividad empresarial agraria y alimentaria en el mercado interior. En concreto, por cuanto incluye un listado mínimo e indicativo de prácticas comerciales prohibidas cuando se ejercen entre proveedores y compradores y un conjunto de indicaciones contractuales que de modo necesario se han de observar en las relaciones comerciales. Pero, además, es relevante la previsión de la precisa coordinación entre las autoridades de control u órganos públicos independientes con capacidad de sancionar, así como de iniciar una investigación de oficio y de recibir las denuncias presentadas por parte de los particulares. Aspectos que van a contribuir a favorecer la aplicación de las medidas disuasorias respecto de las actuaciones contrarias a la lealtad en dicho ámbito.

La reconocida discrecionalidad de los Estados miembros al momento de transponer las disposiciones comunitarias les permiten recoger en sus ordenamientos medidas más limitativas. En el caso nacional, la aprobación de la Directiva (UE) 2019/633 ha hecho necesaria la revisión del contenido de la precursora Ley 12/2013 de medidas para la mejora del funcionamiento de la cadena alimentaria que, a pesar de haber sido referente en el ámbito comunitario, debe adecuar su contenido en algunos aspectos. El Anteproyecto y la actual Ley 16/2021 por la que se modifica la Ley $12 / 2013$, apreciamos que supone un refuerzo del sector en la medida en que limita la venta a pérdida o la destrucción del valor en la cadena y, a su vez, precisa la obligación de que el precio acordado entre productores y compradores cubra, como mínimo, los costes de producción. Sin embargo, pese a estas bondades en su contenido, el Informe elaborado por la CNMC a aquél no fue favorable en su totalidad. La CNMC concluyó que la propuesta resulta ineficiente en materia de competencia. Básicamente por la ajustada relación existente entre la norma sectorial y las disposiciones jurídicas sobre competencia y la falta de determinación de la aplicación de cada una de estas ramas, a pesar de que aquélla trate de complementar la ordenación de la competencia en el mercado nacional. Además de ésta, se plantean otras cuestiones prácticas, como lo son: el ámbito de aplicación a todas las relaciones comerciales sin 
concretar la existencia del desequilibrio en la misma; la ausencia de delimitación de los contratos tipo y los contratos alimentarios; la necesidad de simplificar el régimen sancionador o, en su caso, la previsión de medidas de coordinación entre el régimen sancionador en el sector agroalimentario y el resto de regímenes y autoridades sancionadoras; y, al igual, el impulso de mecanismos de cooperación de la AICA y las administraciones sectoriales y territoriales.

La Ley de cadena alimentaria pretende impedir conductas comerciales desleales en cuanto a los desequilibrios en el poder de negociación de las partes de la relación comercial o situaciones de dependencia, impulsando la tutela de los establecimientos de distribución alimentaria minorista y el incremento del volumen de los productores. Esto es, la cooperación entre los productores y el impulso de las cooperativas. La pretensión se concreta en limitar los abusos de mercado por parte de los operadores de la cadena de valor que son superiores frente al sector vulnerable, a fin de contribuir a la mejora de la competitividad de la cadena agroalimentaria. Las cooperativas y los propios agricultores realizan sus relaciones comerciales con entidades compradoras y distribuidoras de importante tamaño, lo que implica la dependencia económica frente a los mismos por ser sus principales canales comerciales. En definitiva, se hace preciso fortalecer la capacidad de negociación de los eslabones que integran la cadena de valor alimentaria y que actúen en igualdad de condiciones, lo que va a beneficiar la competencia en el sector. De este modo, hay que tratar de ajustar la cadena agroalimentaria de abajo hacia arriba e impedir las conductas abusivas entre los operadores que la conforman.

El problema principal que, en este sentido, también se plantea es la atribución de la potestad sancionadora en lo que se refiere al cumplimiento del contenido del texto normativo y que se ha reconocido a organismos e instituciones administrativos específicos y no a la autoridad en materia de competencia. Razón que nos lleva a considerar que hubiera sido más apropiado evidenciar en su contenido la vinculación entre las previsiones de la norma sectorial y los comportamientos desleales recogidas en la LCD y, en consecuencia, la sujeción al régimen sancionador de ésta. 


\section{Bibliografía}

AMAT LLOMBART, P.: "Contratación de productos agrarios en la cadena alimentaria y prácticas comerciales desleales a propósito de la transposición de la Directiva 2019/633", Revista de derecho agrario y alimentario, no 36(77), 2020, pp. 7-67. ARAUJO BOYD, M. \& FERRER VIEYRA, E.: "La Ley de medidas para mejorar el funcionamiento de la cadena alimentaria. Una visión desde el derecho de la competencia", Gaceta jurídica de la Unión Europea y de la competencia, no 35, 2013, pp. 16-21.

ARIAS VARONA, F.J.: "La armonización europea de la regulación de la cadena alimentaria", La Ley mercantil, no 60, 2019, p. 6.

ARMIJO CHÁVARRI, E. (coord.): Análisis de la reforma del régimen legal de la competencia desleal y la publicidad llevada a cabo por la Ley 29/2009, de 30 de diciembre, Editorial La Ley, Madrid, 2011.

BENEYTO, K. (dir.) \& ARMENGOT VILAPLANA, A. (coord.): Actos de Competencia Desleal y su Tratamiento Procesal, Tirant lo Blanch, València, 2020.

CACHAFEIRO GARCÍA, F., GARCÍA PÉREZ, R. \& LÓPEZ SUÁREZ, M.A. (coords.): Derecho de la competencia y gran distribución, Editorial Aranzadi, Cizur Menor, 2016.

CAZORLA GONZÁLEZ, M.J. \& BARDERA BALDRICH, M.M.: "ANÁLISIS DE LAS RELACIONES COMERCIALES Y DE COMPETENCIA EN LA CADENA DE SUMINISTRO ALIMENTARIA", Revista de derecho agrario y alimentario, no 36(76), 2020, pp. 7-48.

CRESPO PEREIRA, D. \& ARIAS VARONA, FJ.: "Hacia una regulación de la cadena alimentaria", Gaceta jurídica de la Unión Europea y de la competencia, no 33, 2013, pp. 9-18.

CRUZ ROCHE, I. \& PALMA FERNÁNDEZ, J.L.: "La Ley de la Cadena Alimentaria”. En: Distribución comercial: todas las claves de la Distribución desveladas por las grandes compañias del sector (dirs. MUÑOZ DEL CAZ, E. \& ORTEGA BURGOS, E.), Editorial Aranzadi, Cizur Menor, 2017, pp. 1277-1288.

GARCÍA VIDAL, A.: "Prácticas comerciales desleales en la cadena de suministro agrícola y alimentario. Impacto de la Directiva (UE) 2019/633 en el Derecho español”, GA_P. Análisis, 2019, pp. 1-8. 
Enfoques normativos sobre las prácticas desleales en la cadena agroalimentaria...

(pp. 199-240)

GONZÁLEZ CASTILLA, F.: "La represión de las prácticas comerciales desleales en la cadena agroalimentaria europea”. En: Estudios sobre el régimen jurídico de la cadena de distribución agroalimentaria, (dirs. GONZÁLEZ CASTILLA, F. \& RUIZ PERIS, J.I.), Marcial Pons, Ediciones Jurídicas y Sociales, Madrid, 2016, pp. 183-198.

GONZÁLEZ CASTILLA, F. \& RUIZ PERIS, J.I. (dirs.): Estudios sobre el régimen jurídico de la cadena de distribución agroalimentaria, Marcial Pons, Ediciones Jurídicas y Sociales, Madrid, 2017.

MASSAGUER FUENTES, J.: Comentario a la Ley de Competencia Desleal, Civitas, Madrid, 1999.

MASSAGUER FUENTES, J.: El nuevo Derecho contra la competencia desleal. La Directiva 2005/29/CE sobre las Prácticas Comerciales Desleales, Thomson Civitas, Cizur Menor, 2006.

MAUDES GUTIÉRREZ, A. \& SILOS RIBAS, M.: "Valoración de la ley de la cadena alimentaria desde la perspectiva de la promoción de la competencia”. En: Derecho de la competencia y gran distribución (coords. CACHAFEIRO GARCÍA, F., GARCÍA PÉREZ, R. \& LÓPEZ SUÁREZ, M.A.), Editorial Aranzadi, Cizur Menor, 2016, pp. 249-268.

PEINADO GRACIA, J.I. (dir.) \& VÁZQUEZ RUANO, T. (coord.): Tratado de Derecho de sociedades cooperativas, 2 vols., Tirant lo Blanch, València, 2019.

RODRÍGUEZ CACHÓN, T.: "Relaciones contractuales en la cadena alimentaria: análisis a la luz de la nueva regulación", Revista de Derecho Civil (RDC), no 5(1), 2018, pp. 191-227.

SÁNCHEZ HERNÁNDEZ, Á.: "Los contratos alimentarios en la Ley de la calidad alimentaria: referencia a la normativa y doctrina italiana 'dei contratti di cessione dei prodotti agrícola e agroalimentaria”, Actualidad Civil, no 3, 2015, pp. 1-20.

SCHEBESTA, H., VERDONK, T., PURNHAGEN, K.P. \& KEIRSBILCK, B.: "Unfair Trading Practices in the Food Supply Chain: Regulating Right?", European Journal of Risk Regulation (EJRR), no 9(4), 2018, pp. 690-700.

DOI: https://doi.org/10.1017/err.2019.2

TATO PLAZA, A.: "La reforma de la Ley General de Publicidad", Revista de Derecho de la Competencia y la Distribución (RCD), no 7, 2010, pp. 141-154.

TATO PLAZA, A., FERNÁNDEZ CARBALLO-CALERO, P. \& HERRERA PETRUS, C.: La reforma de la ley de Competencia Desleal, Editorial La Ley, Madrid, 2010.

VÁZQUEZ RUANO, T.: "Aspectos de competencia en la comercialización de productos agroalimentarios", Actas de derecho industrial y derecho de autor (ADI), $\mathrm{n}^{\mathrm{o}}$ 38, 2017-2018, pp. 423-440. 
- "Cuestiones de Derecho español sobre publicidad y competencia en el sector agroalimentario", Przeglad Prawa Rolnego, no 1(16), 2015, pp. 245-263.

VICIANO PASTOR, J.: "Algunas reflexiones (críticas) sobre la Ley 12/2013 de la cadena alimentaria de medidas para mejorar el funcionamiento de la cadena alimentaria”. En: Estudios sobre el régimen jurídico de la cadena de distribución agroalimentaria (dirs. GONZÁLEZ CASTILLA, F. \& RUIZ PERIS, J.L.), Marcial Pons, Ediciones Jurídicas y Sociales, Madrid, 2016, pp. 171-182.

VICIANO PASTOR, J. (dir.) \& CORBERÁ MARTÍNEZ, J.M. (coord.): Retos en el Sector Agroalimentario Valenciano en el Siglo XXI, Tirant lo Blanch, València, 2019. 